\title{
Development status and trend of agricultural robot technology
}

\author{
Yucheng Jin ${ }^{1}$, Jizhan Liu ${ }^{1 *}$, Zhujie Xu${ }^{1}$, Shouqi Yuan ${ }^{1}$, Pingping Li ${ }^{2}$, Jizhang Wang ${ }^{1}$ \\ (1. Key Laboratory of Modern Agricultural Equipment and Technology, Ministry of Education, Jiangsu University, \\ Zhenjiang 212013, Jiangsu, China; \\ 2. College of Biology and the Environment, Nanjing Forestry University, Nanjing 210042, China)
}

\begin{abstract}
In the face of the contradiction between the increasing demand for agricultural products and the sharp reduction of agricultural resources and labor force, agricultural robot technology is developing explosively on the basis of decades of technical and industrial exploration. In view of the complexity and particularity of the development of agricultural robot technology, it is of great value to summarize its development characteristics and make reasonable judgments on its development trend. In this paper, the type of agricultural robot systems was first discussed. From the classification of agricultural robot systems, the development of main types of monitoring robots, non-selective and selective working robots for crop farming, livestock and poultry farming and aquaculture were introduced in detail. Then the scientific research, core technology, and commercialization of different types of agricultural robots were summarized. It is believed that navigation in complex agricultural environments, damage-free robot-crop interaction, and agronomy-robot fusion have high scientific value and significance to promote the revolutionary advances in agricultural robot technology. The characteristics of inter-discipline between agricultural robot technology and new materials, artificial intelligence, bionics, agronomy are research focus. The fast damage-free operation, autonomous navigation for complex environments, target detection for complex backgrounds, and special design for agricultural robots are considered to be the key technology of agricultural robot development, and the development path is given. Finally, robot-crop interaction simulation, big data support, and artificial intelligence are regarded as paths to realize the breakthrough of key agricultural robot technologies. The summary and prospect of this paper are of positive significance to promote the overall development of agricultural robot technology.
\end{abstract}

Keywords: agricultural robot, type, selective, non-selective, trend

DOI: $10.25165 /$ j.ijabe.20211404.6821

Citation: Jin Y C, Liu J Z, Xu Z J, Yuan S Q, Li P P, Wang J Z. Development status and trend of agricultural robot technology. Int J Agric \& Biol Eng, 2021; 14(4): 1-19.

\section{Introduction}

Today, with a global population of 7594 million, 430000 people are still born every day. At the same time, the demand for agricultural products continues to increase as living standards rise. Correspondingly, the world's arable land and other agricultural production resources are shrinking. With fewer agricultural resources to carry a huge pressure of larger and higher demand for food, it is objectively required to fully release the potential of agricultural production with modern technology. Meanwhile, the aging of the population and the sharp decline of the agricultural population objectively require more intelligent and even unmanned ways to ensure agricultural production. Agricultural activities still rely heavily on human labor, because agricultural tasks are considered "hard work" and low profitability, youngsters are looking for job opportunities in urban regions, so farmers are looking for new ways to automate their farms and thus recover any

\section{Received date:2021-06-07 Accepted date: 2021-07-20}

Biographies: Yucheng Jin, PhD candidate, Associate Professor, research interest: agricultural robot technology, Email: Mike2004@126.com; Zhujie Xu, Master candidate, research interest: agricultural robot technology, Email: 1119050967@, qq.com; Shouqi Yuan, PhD, Professor, research interest: agricultural engineering, Email: shouqiy@ujs.edu.cn; Pingping Li, PhD, Professor, research interest: agricultural engineering, Email: lipingping@njfu.edu.cn; Jizhang Wang, PhD, Associate Professor, research interest: agricultural informatization, Email: whxh@ujs.edu.cn.

*Corresponding author: Jizhan Liu, PhD, Professor, research interest: agricultural robot technology. Key Laboratory of Modern Agricultural Equipment and Technology, Ministry of Education, Jiangsu University, No.301, Xuefu Road, Zhenjiang 212013, China. Tel: +86-13861392051, Email: liujizhan@163.com. $\operatorname{losses}^{[1]}$. As a representative way and an inevitable trend of agricultural intelligence and modernization, agricultural robot technology is embracing unprecedented development opportunities today.

The development of agricultural robot technology is the inevitable requirement of agriculture from the 1.0 era to the 4.0 era, and its fundamental task is not only to solve the problem of less labor, precision, safety, comfort and green operation which is difficult to realize with traditional agricultural machinery and equipment but also to fill the blank fields that many traditional types of agricultural machinery cannot do. Although there are still many cases in which robots are not as fast as humans, agriculture is currently developing robotic systems to work in the field and help producers with tedious tasks, pushing agricultural systems to the new concept of Agriculture 5.0 $0^{[2]}$.

However, the development of agricultural robots has a special complexity. Firstly, it has a high degree of inter-discipline. Based on the high integrity of mechanical - electronic - information control of robot technology itself, biometric and statistics are further integrated into their own to the fragility, growth, and individual differences of biological objects. Secondly, as a new technology, the development of agricultural robots depends on the complicated research chain among basic data, basic models, key technologies, and equipment development. Thirdly, compared with the traditional agricultural machinery which matches the mechanical manufacturing chain with a few electronic components and meters, the agricultural robot industry chain is more complex. At present, there is still a great distance between the current development level of agricultural robots and the actual demand for agricultural 
production. It is of positive significance to the development of agricultural robot technology and industry to summarize its development characteristics under the conditions of the new times and make reasonable judgments on its development trend and direction.

\section{Development of agricultural robot systems}

\subsection{Types of agricultural robot systems}

At present, there are different domain definitions and classification methods of agricultural robots. As shown in Table 1, agricultural robot technology has been studied and applied widely in planting, livestock and poultry farming, aquaculture. In crop farming, agricultural robots for phenotyping ${ }^{[3,4]}$, monitoring, mapping, crop managing, environment control, etc., are available. Similarly, in livestock and poultry farming and aquaculture, agricultural robots can perform functions of phenotyping ${ }^{[3]}$, monitoring, managing, environment control, etc. For crop farming, the research and development of agricultural robots have covered open field production, semi-closed greenhouses production and fully enclosed plant factory production, as well as every task of tillaging, grafting ${ }^{[5,6]}$, planting, fertilizing, pollination, spraying, harvesting, grading, etc. The robotic solutions can also be categorized into airborne, earthbound, and aquiclude solutions ${ }^{[7]}$. If combining the operation implementation mode and the technical level, the agricultural robots can be divided into two categories: the non-selective working robots and the selective working robots. Non-selective working robots do not distinguish the target individual in working. On the contrary, selective working robots need to realize the selective operation of individual agricultural targets through the identification, positioning, and diagnosis of them based on machine vision or other sensing technologies.

\section{Table 1 Classification of agricultural robot systems}

\begin{tabular}{|c|c|}
\hline Aspect & Type \\
\hline Type of industry & Crop farming, livestock and poultry farming, aquaculture \\
\hline Function & $\begin{array}{l}\text { Phenotyping, monitoring, mapping, object handling, } \\
\text { environment cleaning, health protection, etc. }\end{array}$ \\
\hline Intelligent level & Remote-control, man-robot collaboration, full autonomous \\
\hline Working mode & Selective, non-selective \\
\hline Mobility & Stationary, mobile \\
\hline Space & Aerial, ground, aquiclude \\
\hline
\end{tabular}

\subsection{Development of agricultural monitoring robots}

2.2.1 Monitoring robots in crop farming

In agricultural production, monitoring plays a vital role which is the foundation of achieving precision agriculture. The distance between crops and satellites is considerable, typically around $700 \mathrm{~km}$, and deeper insights are reachable when sensors remain closer to the targets; for aircraft systems, the distance to land can be around $100 \mathrm{~m}$; when monitoring platforms operate from the ground, the distance from the sensors to the target crop diminishes to less than $2 \mathrm{~m}^{[2,8]}$. As these vehicles move near the crop, the data acquired increase in accuracy, and resolutions of one or more samples per meter are feasible ${ }^{[2]}$. Today, UAVs have been adopted widely in crop farming monitoring, ground robotic vehicles are also developed rapidly for different scenarios of soil moisture, $\mathrm{pH}$, fertility monitoring and climate conditions monitoring, crop plant diseases and insect pests monitoring, growth and yield monitoring, etc. (Table 2)

Table 2 Monitoring robots in crop farming

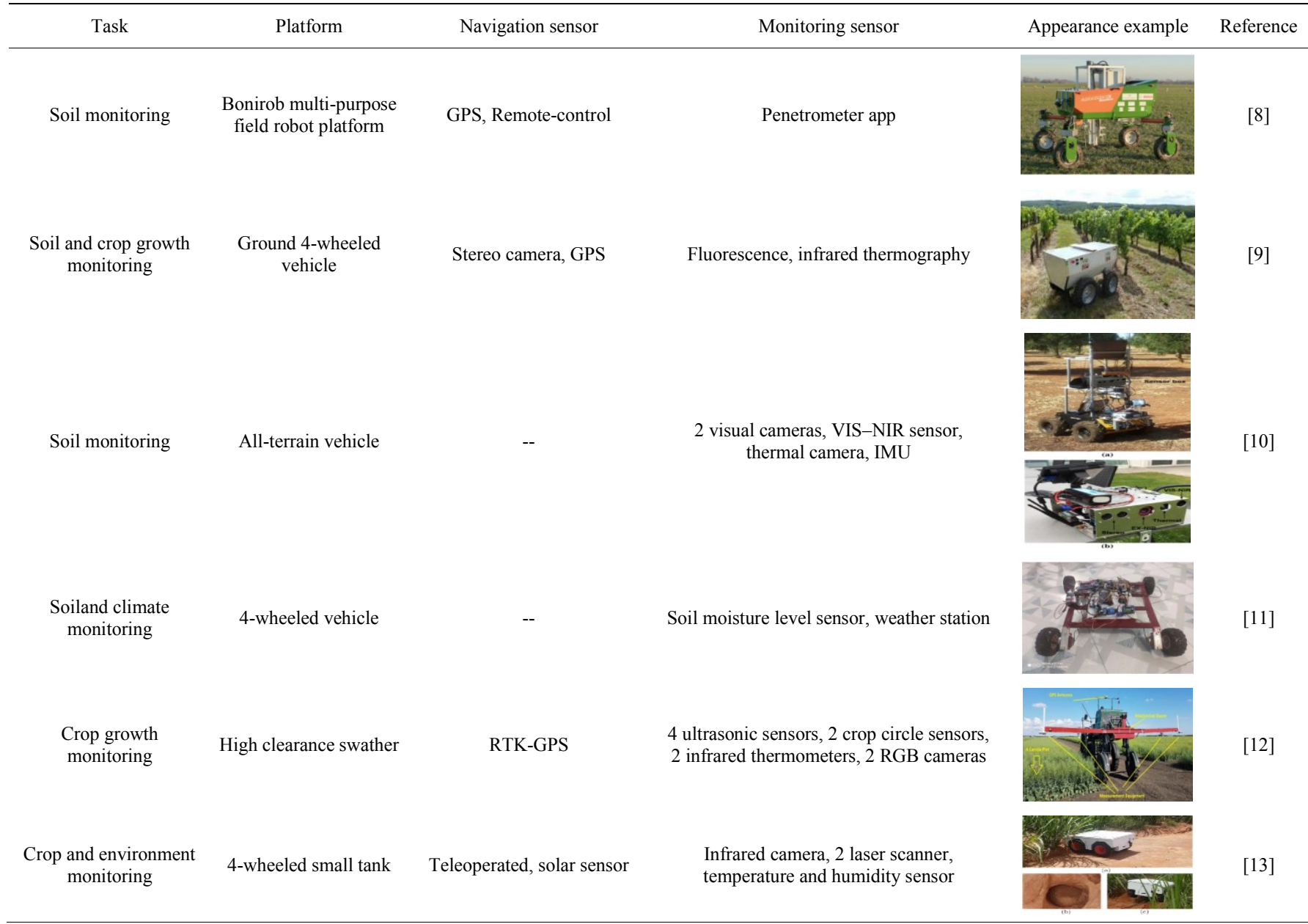




\begin{tabular}{|c|c|c|c|c|c|}
\hline Task & Platform & Navigation sensor & Monitoring sensor & Appearance example & Reference \\
\hline Crop monitoring & $\begin{array}{l}\text { 4WD Electric } \\
\text { Monster Truck }\end{array}$ & $\begin{array}{l}\text { Laser range finder, } \\
\text { IMU, GPS }\end{array}$ & Infrared camera, RGB camera & & {$[14]$} \\
\hline $\begin{array}{l}\text { Plant growth } \\
\text { monitoring }\end{array}$ & -- & -- & Colour zoom camera, RGB color sensors & & {$[15]$} \\
\hline Yield monitoring & $\begin{array}{l}\text { 4-Wheel } \\
\text { Cart }\end{array}$ & Barcode reader & Electronic balance & & {$[16]$} \\
\hline $\begin{array}{l}\text { Plant health } \\
\text { monitoring }\end{array}$ & $\begin{array}{l}\text { 5-Wheel } \\
\text { 6-chassis }\end{array}$ & Ultrasonic sensor & RGB camera, NIR camera & & {$[17]$} \\
\hline $\begin{array}{l}\text { Plant growth and } \\
\text { health monitoring }\end{array}$ & tracked binscarrier & -- & 2 Lidars, 6 crop sensors & & {$[18,19]$} \\
\hline $\begin{array}{l}\text { Plant growth } \\
\text { monitoring }\end{array}$ & 4-wheel frame & 2 cameras (front-back) & -- & & {$[20]$} \\
\hline $\begin{array}{l}\text { Plant health } \\
\text { monitoring }\end{array}$ & 4-wheeled vehicles & $\begin{array}{l}\text { GPS and IMU,stereo camera } \\
\text { and the 3D Lidar }\end{array}$ & $\begin{array}{c}\text { 3D scanner (using } \\
\text { a 2D laser attached to the arm) }\end{array}$ & & {$[21]$} \\
\hline Crop disease detection & 4-wheel vehicle & 2D laser LiDAR,GPS,IMU & $\begin{array}{l}2 \text { digital single-lens reflex cameras, } \\
\text { multispectral camera, hyperspectral } \\
\text { system, thermal camera }\end{array}$ & & {$[22]$} \\
\hline $\begin{array}{l}\text { Pests and } \\
\text { diseases }\end{array}$ & $\begin{array}{l}\text { A frame with four } \\
\text { fat-bike wheels }\end{array}$ & Remote-controlled & $\begin{array}{c}\text { A multispectral camera, } \\
\text { three DSLR cameras, } \\
\text { a hyperspectral imaging system, } \\
\text { a thermal camera }\end{array}$ & & {$[23]$} \\
\hline
\end{tabular}

Scholz et al. ${ }^{[8]}$ developed an automatic soil penetrometer, which was integrated into an autonomous mobile robot named Bonirob, field measurements have been performed by using the robot in two modes: a "manual mode", where the user controls the system via a remote control panel, and an "automatic mode" where the robot acts completely automatic. The European Union VineRobot project involves eight partner groups from the wine-making countries of France, Italy, Germany, and Spain, have developed an autonomous robot that will measure vineyard parameters (vegetative growth, grape yield, grape composition, and soil moisture) on-the-go in a non-invasive way to help winemaking decisions ${ }^{[9,10]}$. The follow-up VineScout project funding from the European Union's Seventh Programme VineScout is working to develop an autonomous vineyard monitoring robot that can help wine producers measure key vineyard parameters, including water availability, vine leaf/canopy temperature, and variations in plant vigor. Control of plagues, fungi, and other threats are recurrent tasks in winery ${ }^{[24]}$.
The GRAPE project, founded by the Echord++ program from European Commission, has developed the monitoring robot that is consisted of the automatic pheromone dispenser distribution for matting disruption in vineyards using an autonomous ground robot equipped with a robotic $\mathrm{arm}^{[21]}$. To realize row crop navigation for crop scouting, Austin Schmitz proposed an unmanned ground vehicle structure with reconfigurable parallel and linear configurations to accomplish both inter-row maneuvering and moving from one row to the next (Figure 1$)^{[25]}$.

Satellites must be integrated by UAV and unmanned platforms to construct multi-sensorial systems that operate at different spatial scales (where), temporal (when), and spectral (what), to increase the spatial and also spectral resolution ${ }^{[26]}$. The Flourish project, funded by the European Community's Horizon 2020 program, is developing an adaptable robotic solution for precision farming ${ }^{[27]}$. Combining the aerial survey capabilities of a small autonomous multi-copter Unmanned Aerial Vehicle (UAV) with a multi-purpose agricultural 
Unmanned Ground Vehicle (UGV) (Figure 2), the system will be able to survey the field from the air, perform a targeted intervention on the ground, and provide detailed information for decision support, all with minimal user intervention ${ }^{[27]}$.

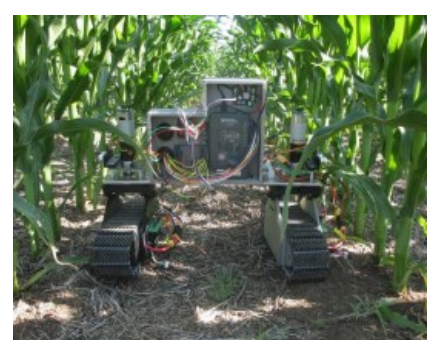

a. Parallel configuration

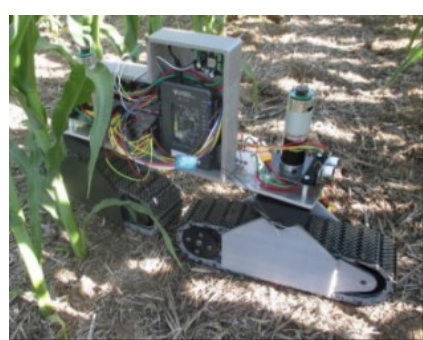

b. Linear configuration
Figure 1 Autonomous parallel-linear ground vehicle for row crop scouting $^{[25]}$

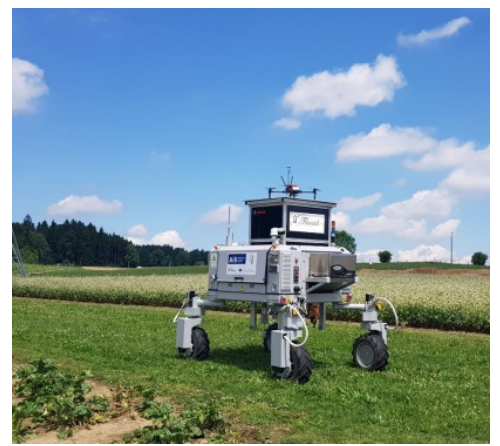

Figure 2 Unmanned ground vehicle Bonirob, carrying an unmanned aerial vehicle ${ }^{[27]}$

Although robotic monitoring technology is developing so rapidly, and so many types of sensors are integrated to get big data, accurate and efficient autonomous monitoring remains a challenge.
Taking early crop disease monitoring as an example, for farmers, it is hoped that robots can detect diseases in certain leave or fruit rather than canopy groups in real-time without any operation. It is a very difficult task, involving autonomous crop target panoramic information acquisition, disease location locking and disease type diagnosis based on multi-information fusion, and so on. It is necessary to further improve the friendliness of big data to farmers and to give direct decisions to end-users.

2.2.2 Monitoring robots in livestock and poultry farming and aquaculture

Poultry houses require daily monitoring to ensure animal health and proper house operation ${ }^{[28]}$. Maintaining the health and welfare status of livestock at optimal levels has traditionally been a main concern of farmers, and more recently, consumers ${ }^{[28]}$. Today more and more are engaged in the development of robotic monitoring in livestock and poultry farming (Table 3 ). The air quality inside a livestock building is more and more taken seriously by both farmers and researchers ${ }^{[29]}$. Sub-optimal air quality not only could influence the productivity of farm animals, as well as the health and well-being of livestock and workers, but also will affect the healthy and sustainable development of the livestock and poultry industry ${ }^{[30]}$ As the indoor environmental parameters distribution in livestock and poultry buildings is inhomogeneity, they needed to be monitored frequently, flexibly, freely ${ }^{[30]}$. Therefore, robotic monitoring is highly represented. The robot was developed by Qi et al. ${ }^{[30]}$ used an off-the-shelf vehicle installed with a 9 DOF MEMS IMU sensor, and measurement sensors (temperature, relative humidity, and dust sensors) were fixed. In livestock and poultry farming, the outbreaks of various diseases and epidemics will bring huge losses. In order to tackle these diseases, it is necessary to implement farm scientific technology for the monitoring of health to reduce production costs ${ }^{[31]}$. Today, wearable devices such as foot earrings

\section{Table 3 Monitoring robots in livestock and poultry farming and aquaculture}

\begin{tabular}{|c|c|c|c|c|c|}
\hline Function & Platform & Navigation sensor & Monitoring sensor & Appearance example & Reference \\
\hline Air quality monitoring & 4-wheel vehicle chassis & IMU sensor & $\begin{array}{l}\text { Temperature sensor, relative } \\
\text { humidity sensor, dust sensor }\end{array}$ & & {$[30]$} \\
\hline Health monitoring & Milking robot & -- & 6 strain gages, laser distance sensor & & {$[32]$} \\
\hline Health monitoring & Milking robot & -- & 3 strain gauge scales, 3 web cameras & -- & {$[33]$} \\
\hline Bunk monitoring & Clearpath Robotics & $\begin{array}{l}\text { RTK GNSS, } \\
\text { multi-layer lidar }\end{array}$ & Bunk scanner & & {$[34]$} \\
\hline Water quality monitoring & Four-wheel chassis & Monorail, sonar & Water quality sonde & & {$[35]$} \\
\hline Water quality monitoring & $\begin{array}{l}\text { Casing with main frame } \\
\text { and side plates }\end{array}$ & BDS/INS & $\begin{array}{l}\text { Temperature sensor, } \mathrm{pH} \text { sensor, } \\
\text { dissolved oxygen sensor }\end{array}$ & & {$[36]$} \\
\hline $\begin{array}{l}\text { Feeding and water } \\
\text { monitoring }\end{array}$ & Four-wheel chassis & Monorail, sonar & Physicochemical sensors & & {$[37]$} \\
\hline
\end{tabular}


and ear clips have been widely used in the health monitoring of animals and chickens. By contrast, integrating an automatic cow health measurement system into a milking robot is more feasible and low-cost in dairy ${ }^{[32,33]}$. With the system developed by Pastell et al. ${ }^{[32,33]}$, the information about the leg weight of cows is measured with four balance platforms and the respiration rate is extracted from the data of a laser distance sensor pointing at the cow's side. Each measurement begins when the robot starts milking and ends when the milking ends, and the total weight and the number of kicks with each leg are calculated ${ }^{[32,33]}$. The data can be used for automatic detection of leg problems and the symptoms of heat stress can probably be detected as increased respiration rate ${ }^{[32]}$. Assessment of feed remaining in bunks (calling) is a critically important job at a beef feedlot ${ }^{[33]}$. Supported by the Australian Government, MLA (Meat \& Livestock Australia Limited) developed a bunk calling robot named BunkBot, which could provide highly repeatable (precise) and accurate feed remaining predictions during the validation experiment in a commercial feedlot environment ${ }^{[34]}$.

Aquaculture produces and breeds fish, shrimp, and clams under controlled conditions, physicochemical parameters, such as dissolved oxygen, $\mathrm{pH}$, salinity, and temperature, must be measured in real-time to provide data for carrying out corrective actions and maintaining optimal conditions of production ${ }^{[35]}$. Considering the diversity and variability of the breeding environments, in order to obtain more comprehensive information, it is often required to install multiple monitoring equipment in more positions, which would greatly increase the procurement and maintenance costs. Compared with measurement equipment installed in fixed positions, the flexibility of the water quality detection robot has obvious advantages ${ }^{[36]}$. According to Table 3, the robot was designed by Huang et al. used the BDS module for surface navigation and used the water quality detection module, to collect parameters such as the water temperature, $\mathrm{pH}$ value, and dissolved oxygen (DO) content of the freshwater aquaculture environment ${ }^{[37]}$. The robot developed by Fernando travels automatically on a monorail to dispense the food and measure the water parameters ${ }^{[35,37]}$. Local and remote experiments were performed to show the usefulness of the robot operation via the Internet for intensive cultivation of the freshwater red claw crayfish ${ }^{[35]}$. Livanos et al. ${ }^{[38]}$ developed a smart autonomous underwater vehicle with intelligent optical navigation to enable automated inspection of aquaculture net-pen cages.

\subsection{Development of non-selective agricultural working robots}

\subsubsection{Unmanned agricultural machinery in crop farming}

At present, the research and development of various agricultural robot equipment are flourishing and rapidly extends from the laboratory to the enterprise and production. In the field of non-selective agricultural working robots represented by field navigated and unmanned agricultural machinery, the research on GNSS-IMU integrated navigation technology of agricultural machinery systems has become mature, and the agricultural machinery navigation system has been productized. Grass cutting is the most fundamental but tedious task $\mathrm{k}^{[39,40]}$. Remote-controlled and autonomous robotic lawn mowers guided by global navigation satellite systems are welcomed ${ }^{[41,42]}$. More and more robotic lawn mowings are incorporated with GPS, cameras, ultrasonic sensors to have performances of detection and avoidance of obstacles ${ }^{[43]}$. For in-row spraying, tilling, ditching, etc., in fields, greenhouse, orchards, and vineyards, local navigation with machine vision, Lidar or RGB-D fusion is a research hotspot ${ }^{[44-46]}$. Liu also developed an autonomous transplanter of strawberry plug seedlings and automatic mobile substrate paver for elevated cultivation navigated with an arc array of photoelectric switches ${ }^{[47-49]}$, and a high-ridge automatic transplanter for strawberry plug seedlings with a profiling walking device ${ }^{[50]}$.

2.3.2 Unmanned agricultural machinery in livestock and poultry farming and aquaculture

High-density livestock and poultry breeding pose a great challenge to environmental security ${ }^{[51]}$. Disinfection is the most basic, effective, and extensive way of epidemic prevention in the process of livestock and poultry breeding ${ }^{[51]}$. Due to the high frequency of disinfection, strict operation standards, and poor working conditions, it is of great significance to develop and apply automatic disinfection equipment to ensure the high efficiency and safe production of livestock and poultry breeding ${ }^{[1,52]}$. A crawler-type disinfection robot that used a sprayer with a gas-liquid extraneous mixture structure was developed ${ }^{[51,52]}$. It could move along the line marked with the magnet and RFID label on the ground to meet the need for the high-flow and long-range spray ${ }^{[51]}$. It is also important to maintain clean and dry ground in livestock and poultry house, automatic alley scrapers with a cable or a shuttle drive are effective in pushing manure through slats, robotic slat cleaners without cables can be programmed to scrape the areas in the barn where manure builds up the most ${ }^{[33]}$. Since there are not only static obstacles, such as the stable but also dynamic obstacles, such as people and livestock, obstacle detection with ultrasonic sensors, etc., is necessary ${ }^{[53,54]}$. If a robotic slat cleaner encounters people or livestock in the alley, it will shut down or go around ${ }^{[53]}$.

In aquaculture, feeding is the primary factor determining efficiency and $\operatorname{cost}^{[55]}$. In order to address the issues of nonuniform feeding and high labor cost plaguing the process of farming Chinese river crabs, Ruan et al. ${ }^{[56,57]}$ proposed a multifunctional automatic river crab feeding boat based on GPS/INS integrated navigation. Pribadi et al. ${ }^{[58]}$ designed a fish feeder robot based on ArduinoAndroid. $\mathrm{Hu}$ et al. ${ }^{[59]}$ proposed a fishpond cleaning robot based on SLAM technology in industrial aquaculture. Kaizu et al. ${ }^{[60]}$ designed a robotic boat for mowing aquatic weeds, which is automatically controlled by the real-time kinematic global navigational satellite system (RTK-GNSS).

2.3.3 Commercial non-selective agricultural working robots

John Deere has developed unmanned deformable tractors (Figure 3a). Kubota company has pioneered the driverless farming machine "SL60A" in Japan, and Russia's Rostov Agricultural Machinery Group's driverless combine harvester will go into production in 2023. In 2018, the Telematics Industry Application Alliance (TIAA) of China organized Jiangsu University and other units to launch the first national full-course unmanned agricultural machinery working demonstration in Xinghua City, Jiangsu Province, China, and then continued to carry out such demonstrations in Jiansanjiang and other areas. Research and development of unmanned agricultural machinery in China has rapidly formed an upsurge. YTO Group Corporation (Figure 3b), FJ Dynamics, ZoomLion Heavy Machinery, etc., have launched unmanned tractors, rice transplanters, harvesters, and other products, and quickly put them into the market and agricultural production.

The unmanned agricultural machinery based on vision, laser radar, and other navigation and combined with the global positioning system has also got the attention paid by the enterprises. An American firm of Rabbit Tractors has developed an autonomous agricultural robot that can run 12 cameras and 4 lidar sensors simultaneously to handle multiple tasks. Clearpath Robotics has developed the Dajeon driverless chassis (Figure 4a). Autonomous 
Solutions has developed the Forge agricultural robot platform for vineyard applications. Autonomous Tractor has developed modular driverless tractors. Kinze Manufacturing has developed autonomous tractors and grain trucks (Figure $4 b$ ).

Compared with crop farming industries, the environment of livestock and poultry farming buildings is more regular and easier to realize unmanned operation. Milking robots that refer to stationary automatic milking systems have been used widely in dairy farms. Animal feeding robots that auto-drive through the barn produced by Hetwin, Lely, GEA and other companies have been applied for several years (Figure 5a). Ramsta Robotics, Washpower, Kyodo, etc., supply robot cleaners to clean out livestock and poultry houses automatically by spraying water at high pressure. Barn floor cleaning robots are also supplied by Lely, Hetwin, etc. In aquaculture, FFAZ supplies a type of automatic feeding robot that travels on the water surface to deliver precise amounts according to the plan of each enclosure and at designated intervals (Figure 5b). Underwater drones produced by Deep Trekker are used to monitor eating habits and monitor for damage to nets.

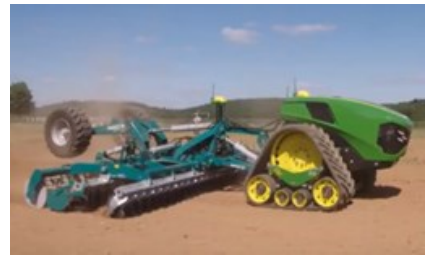

a. John Deere

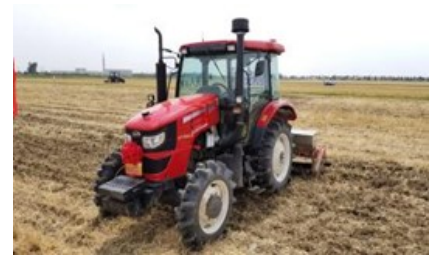

b. YTO Group
Figure 3 Unmanned agricultural machineries based on GNSS-IMU combined navigation

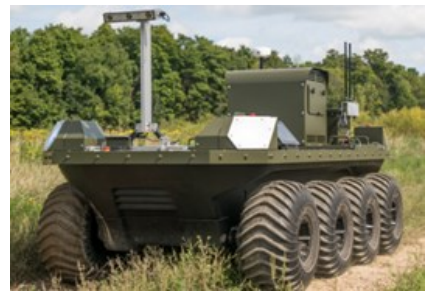

a. Clearpath robotics

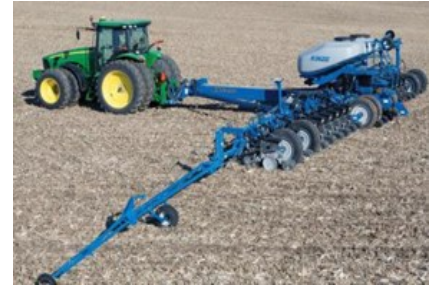

b. Kinze manufacturing
Figure 4 Unmanned agricultural machineries based on other navigation

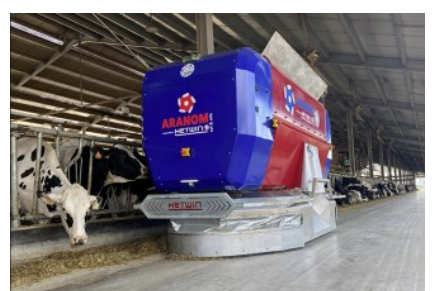

a. Animal feeding

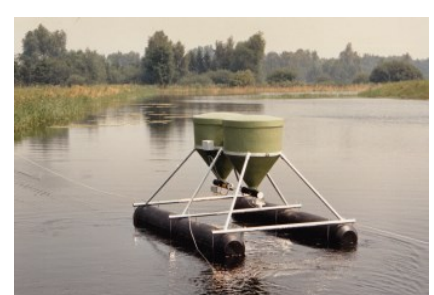

b. Fish feeding
Figure 5 Unmanned feeding machinery in livestock and poultry farming and aquaculture

\subsection{Development of selective agricultural working robots}

\subsubsection{Selective harvesting robots}

Compared with non-selective working, robotic selective working faces a great challenge in the highly textured agricultural environment ${ }^{[61]}$. The characteristics of selective working robots are those types of robotic equipment that need to realize the selective operation of individual agricultural targets through the identification, positioning and diagnosis of them based on machine vision and other technologies. Considering the high labor cost of fresh-eating fruit harvesting, harvesting is undoubtedly the earliest and largest research field of agricultural robot technology. Significant progress has been made in decades of research and development, more work is required in order to reduce the cycle-time before it can be commercially viable and improving operational efficiency has become the most concerned issue in $\mathrm{R} \& \mathrm{D}^{[62]}$. As a result, robotic multi-arm harvesting has been paid more and more attention, it is believed to be able to remarkably improve the harvesting efficiency ${ }^{[63]}$. In general, robotic multi-arm harvesting can be categorized in parallel operation and cooperation (Table 4).

Williams, Zhang, SEPÚLVEDA, Mu, Chen, Li, and Liu et al. ${ }^{[64-76]}$, have developed multi-arm robots for kiwifruit, tomato and grape harvesting and other high-density fruit respectively. Facing the new demand of the new urban production-leisure integrated industry, different humanoid dual-arm harvesting robots have been developed by Peng, and Chen et al. ${ }^{[69,70]}$, which adopt parallel operation mode with the help of on-head RGB-D cameras and in-hand RGB-D cameras. It is believed to achieve a much higher combined harvesting rate with several arms and end-effectors to work at the same time ${ }^{[61,62]}$. However, the harvest zones and harvest order planning are the essential and big challenges to realize the multiplication of efficiency ${ }^{[63,66,70-72]}$.

To harvest fruits by the cooperation of different arms is another selection. Inspired by artificial operation, Liu et al. ${ }^{[73]}$ designed a wolfberry harvesting robot that adopts dual-arm to branch-gripping end-effectors to work together. Joseph et al. ${ }^{[74]}$ designed a dual-arm robot for apple harvesting, results from laboratory studies showed the pick-and-catch coordination resulted in a fifty percent reduction in harvesting cycle time compared to the pick-and-place method. Zhao et al. ${ }^{[75,76]}$ designed a dual-arm robot for harvesting tomato fruits, which used a saw cutting end-effector to cut the stem and the other end-effector to grasp the tomato for avoiding tomato shaking caused by the cutting operation. It is worth noting that the dual-arm cooperation mode puts forward requirements for manipulator configuration, canopy space and cooperation control. Whether it is the reasonable direction of harvesting robot technology development is worth further exploring.

\subsubsection{Other selective working robots in crop-farming}

In recent years, precision agriculture (PA) is emerging rapidly worldwide. The term Precision Agriculture is described as being "a management strategy that uses electronic information and other technologies to gather, process, and analyze spatial and temporal data for the purpose of guiding targeted actions that improve efficiency, productivity, and sustainability of agricultural operations" "[1]. Robotic technology is a powerful tool to realize targeted actions in agriculture, which usually rely on machine vision or other sensing technologies to perform selective or targeted working of seed sowing ${ }^{[77]}$, Seedling sorting/replanting ${ }^{[78]}$, spraying $^{[79,80]}$ weeding ${ }^{[81]}$, pruning ${ }^{[82,83]}$, trimming ${ }^{[60,84-86]}$, flower or fruit thinning ${ }^{[87,88]}$, fruit bagging ${ }^{[87,89,90]}$, de-leafing ${ }^{[91,92]}$, pollination ${ }^{[93-97]}$, bin-handling ${ }^{[98-100]}$, fruit transportation ${ }^{[101,102]}$, fruit grading $^{[103,104]}$, etc. (Table 5).

For pruning, a robotic system must be able to perceive the $3 \mathrm{D}$ pose of the branch to be cut, as well as move a cutting implement precisely to a cut point while avoiding obstacles such as other branches or structures ${ }^{[83]}$. A fully autonomous system must also be able to choose cut points automatically ${ }^{[83]}$. For trimming, challenges arise to realize the visual servoing control of cutting tools towards the target objects, to represent the correct shape and size of a topiary bush and subsequently deciding where and how much cutting is needed for an overgrown bush ${ }^{[61]}$. The EU H2020 
funded project named TrimBot2020 is trying to investigate the underlying robotics and vision technologies to prototype the next generation of intelligent gardening consumer robots ${ }^{[61,105]}$. The TrimBot2020 robotic platform is based on a modified version of the commercial Bosch Indigo lawn mower on which a Kinova robotic arm is mounted ${ }^{[61]}$. The robot platform is equipped with a pentagon-shaped rig of five pairs of stereo cameras and two circular counter rotating sets of knives, one of these will have sharp edges whereas the other will act as an anvil with blunt edges ${ }^{[61]}$. Compared with trimming, robotic pruning is more difficult, there is still a long way to the practical level.

One urgent challenge facing the agriculture industry is the decline of natural pollinators, the high cost of renting bee colonies and the inadequate pollination ${ }^{[93]}$. The idea of using robots to aid pollination has been considered for more than a decade ${ }^{[95,96]}$. There may be two fundamentally different approaches in robotic pollination, the first approach is the use of a ground platform with a manipulator and some sort of end-effector, the second approach is for the robot to fly in the form of a drone or robotic bee imitation ${ }^{[97]}$. Shi et al. ${ }^{[106]}$ proposed that when the UAV is close to the flowering tomato, the downwash flow blows the pollen from the stamen. Pollen will drift to the pistil under the wind, and then pollination is completed. In the greenhouse experiment, as the height of the flower decreases, the proportion of pollen area in the culture dishes which were placed next to the flower was $0.34 \%, 0.25 \%, 0.32 \%$, $0.69 \%$, which preliminarily verified the possibility of the modified drone for pollination. Berman et al. ${ }^{[107]}$ presented a scalable approach to optimizing robot control policies for a target collective

Table 4 Multi-arm selective fruit harvesting robots

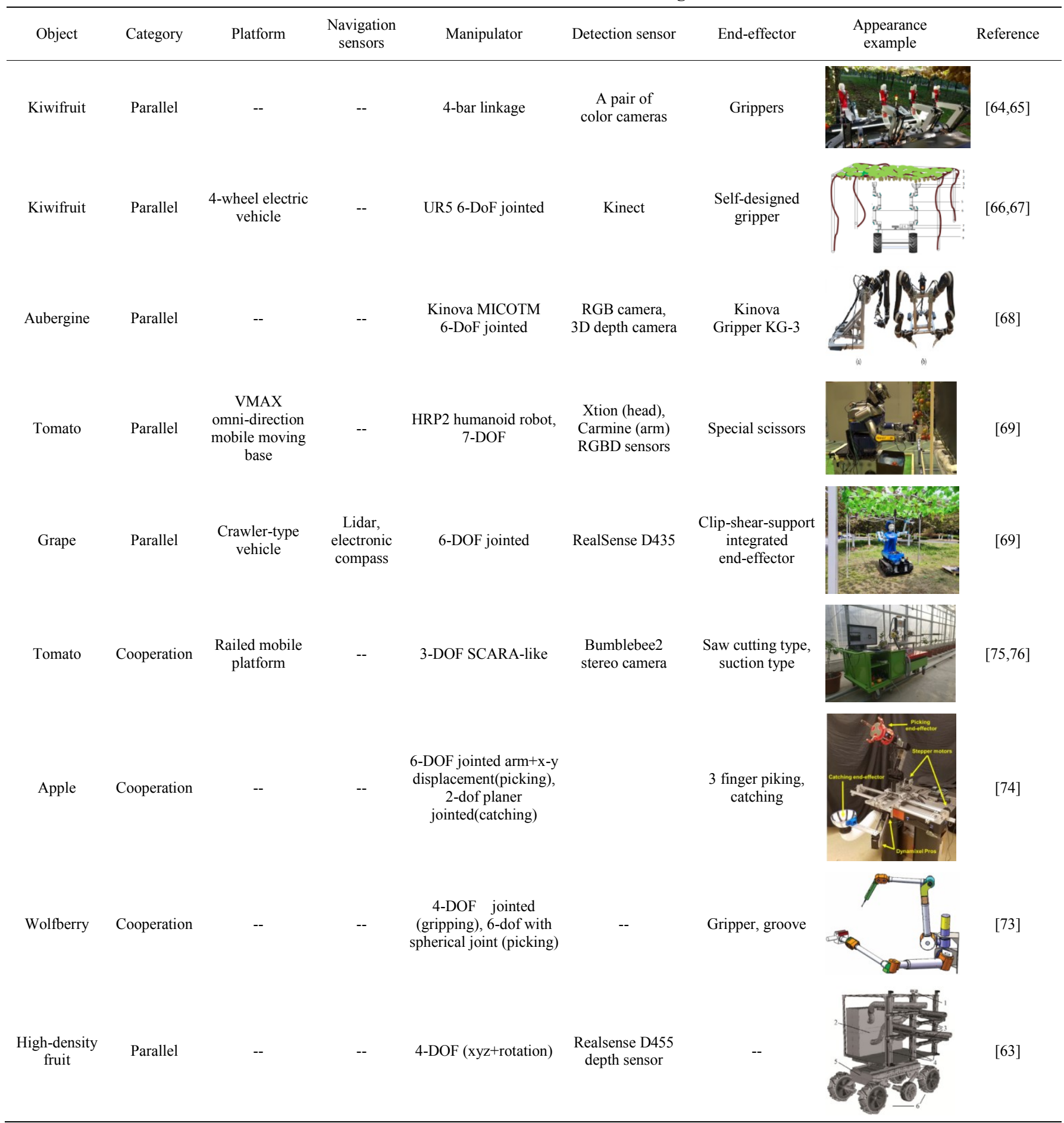


Table 5 Selective working robots in crop-farming except for harvesting robots

\begin{tabular}{|c|c|c|c|c|c|c|}
\hline Task & Platform & Navigation sensor & Detection sensor & Working part & Appearance example & Reference \\
\hline Seed sowing & 4-wheeled platform & Vision sensor & $\begin{array}{l}\text { Ultrasonic sensors and } \\
\text { IR sensors }\end{array}$ & Lead screw and rotating disc & & {$[77]$} \\
\hline $\begin{array}{l}\text { Seedling sorting/ } \\
\text { replanting }\end{array}$ & -- & -- & $\begin{array}{l}\text { RealSense RGB-D } \\
\text { camera }\end{array}$ & Pneumatic grippers & & {$[78]$} \\
\hline Spraying & Electric 4-wheeled platform & Horizontal Lidar & Vertical lidar & $\begin{array}{l}\text { Spraying device with four } \\
\text { independent nozzles }\end{array}$ & & [79] \\
\hline Spraying & $\begin{array}{l}\text { Multifunctional } \\
\text { rubber-tracked vehicle }\end{array}$ & $\begin{array}{l}\text { RTK-DGPS GNSS } \\
\text { receiver, attitude and } \\
\text { AHRS }\end{array}$ & $\begin{array}{l}\text { Stereo camera, } \\
\text { sick laser scanner }\end{array}$ & Smart spraying system & & {$[80]$} \\
\hline Weeding & $\begin{array}{l}\text { Crawler-type autonomous } \\
\text { caterpillar robot "Phoenix" }\end{array}$ & $\begin{array}{l}\text { IMU, Sick LMS111 2D } \\
\text { laser scanner }\end{array}$ & $\begin{array}{l}\text { Sonar sensor } \\
\text { pico }+100 / \mathrm{U}\end{array}$ & $\begin{array}{l}\text { Rotary weeder from humus } \\
\text { co. called "humus planet" }\end{array}$ & & {$[81]$} \\
\hline Pruning & $\begin{array}{l}2 \text { wheel mobile platform } \\
\text { from Neobotix }\end{array}$ & SICK laser scanner & $\begin{array}{l}2 \text { Intel Realse D435i } \\
\text { RGBD cameras }\end{array}$ & $\begin{array}{l}\text { A cutting tool with } \\
\text { pruning shear }\end{array}$ & & {$[82]$} \\
\hline Pruning & -- & -- & $\begin{array}{l}\text { RealSense D435 } \\
\text { RGB-D camera }\end{array}$ & $\begin{array}{c}\text { Pneumatically-actuated four-bar } \\
\text { linkage with custom-ground } \\
\text { blades }\end{array}$ & & {$[83]$} \\
\hline Trimming & -- & -- & Stereo camera & Trimming end-effector & & {$[61,84]$} \\
\hline Trimming & $\begin{array}{c}\text { Tree trunk walking with } 4 \\
\text { legs }\end{array}$ & Remote control & -- & Circular saw & & {$[85]$} \\
\hline Trimming & Lawn mower & $\begin{array}{r}\text { Pentagon-shaped rig } \\
\text { cam }\end{array}$ & $\begin{array}{l}\text { of five pairs of stereo } \\
\text { neras }\end{array}$ & $\begin{array}{l}2 \text { circular counter-rotating sets } \\
\text { of knifes }\end{array}$ & & {$[61,84]$} \\
\hline Thinning & -- & -- & $3 \mathrm{D}$ vision system & $\begin{array}{l}\text { Dual-servo rotating } \\
\text { brush }\end{array}$ & & {$[88]$} \\
\hline Bagging & Wheeled mobile platform & $\begin{array}{c}\text { magnetic } \\
\text { navigation sensor }\end{array}$ & $\begin{array}{c}2 \text { OK_AC1210 USB } \\
\text { cameras }\end{array}$ & $\begin{array}{l}\text { Adding two spring leaves on } \\
\text { both sides of the grape bags }\end{array}$ & & [89] \\
\hline Bagging & -- & -- & $\begin{array}{l}\text { Color TV camera with } \\
\text { infrared sensitivity, } \\
\text { photo-electric sensor }\end{array}$ & $\begin{array}{l}\text { End-effector with } \\
\text { spring plates }\end{array}$ & & {$[87,90]$} \\
\hline
\end{tabular}




\begin{tabular}{|c|c|c|c|c|c|c|}
\hline Task & Platform & Navigation sensor & Detection sensor & Working part & Appearance example & Reference \\
\hline De-leafing & Railed vehicle & -- & $\begin{array}{l}\text { Near-infrared-based } \\
\text { computer vision system }\end{array}$ & $\begin{array}{l}\text { Teeth, two electrodes } \\
\text { (thermal cutting) }\end{array}$ & & {$[91]$} \\
\hline Leaf picking & Railed vehicle & -- & -- & $\begin{array}{l}1 \text { picking rotor with a motor, a } \\
\text { pipe, a vacuum cleaner }\end{array}$ & & {$[92]$} \\
\hline Pollination & $\begin{array}{l}\text { ClearPath Robotics }{ }^{\circledR} \\
\text { Husky platform }\end{array}$ & 3D lidar & $\begin{array}{l}\text { To-hand camera, in-hand } \\
\text { depth camera }\end{array}$ & $\begin{array}{l}3 \text { linear actuators, } 1 \text { flexible } \\
\text { member,cotton-tipped brushes }\end{array}$ & & {$[93]$} \\
\hline Pollination & Pedrail type vehicle & $\begin{array}{l}\text { Camera and sonar } \\
\text { sensors }\end{array}$ & Binocular vision system & Nozzle & & {$[94]$} \\
\hline Pollination & $\begin{array}{l}\text { ClearPath Robotics } \\
\text { 4-wheel ground vehicle }\end{array}$ & -- & $\begin{array}{c}\text { Intel RealSense TM D435 } \\
\text { depth-camera }\end{array}$ & $\begin{array}{c}3 \text { linear actuators, } 1 \text { flexible } \\
\text { plate, a cotton padding }\end{array}$ & & {$[95]$} \\
\hline Pollination & $\begin{array}{c}\text { Autonomous multi-purpose } \\
\text { Mobile } \\
\text { platform }\end{array}$ & -- & Cameras, LED light bars & Spray manifolds & & {$[95,97]$} \\
\hline Bin-handling & $\begin{array}{c}\text { 4-wheel-independent-steering } \\
\text { system(4WIS) }\end{array}$ & GPS, IMU & -- & $\begin{array}{c}\text { Forklift actuated by a } \\
\text { scissors-structured lifting } \\
\text { mechanism }\end{array}$ & & {$[98]$} \\
\hline Bin-handling & $\begin{array}{l}\text { Wheel-ground engagement } \\
\text { system (WGES) }\end{array}$ & LMS 111 laser scanner & ultrasonic sensors & Bin lifting & & [99] \\
\hline Bin-handling & $\begin{array}{l}\text { 4-wheel-independent-steering } \\
\text { system (4WIS). }\end{array}$ & GPS, Lidar, & $\begin{array}{l}\text { RTK, GPS, } 2 \text { laser } \\
\text { scanners, }\end{array}$ & Forklift-type bin loading system & & {$[100]$} \\
\hline Transportation & 4-wheel plafform & Ultrasonic sensors & -- & -- & & {$[101,102]$} \\
\hline Grading & -- & -- & $\begin{array}{l}5 \text { progressive scan video } \\
\text { cameras }\end{array}$ & Long-finger gripper & & [103] \\
\hline Grading & Trunk & -- & Camera & -- & & [104] \\
\hline Grading & Railed platform & -- & $\begin{array}{l}\text { Progressive scan video } \\
\text { camera }\end{array}$ & Rotary tray, flexible gripper & 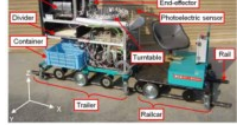 & {$[108]$} \\
\hline
\end{tabular}


behavior in a spatially inhomogeneous robotic swarm, which is illustrated with a scenario in which the behaviors of a swarm of robotic bees are optimized for both uniform and nonuniform pollination of a blueberry field, including in the presence of an unknown wind. However, robotic bees require tethered to power and control so are still a long way off being viable pollinators ${ }^{[97]}$. The ground robotic pollination seems to be more feasible at present, which needs to locate 3D positions of flowers and use physical touching or spraying to finish the pollination. In different researches, detection rates of single flowers may reach $50.0 \%-93.1 \%{ }^{[95-98]}$. Researchers at West Virginia University (WVU) have recently developed an autonomous robot named "BrambleBee" that can pollinate bramble plants within a greenhouse environment. The first-generation end-effector consists of three linear actuators that push and pull a flexible member on which cotton-tipped brushes are inserted ${ }^{[93]}$ (Figure 6a). The second-generation end-effector uses a flexible plate is attached to the linear servos to allow for off-axis flexibility, which is then coated in cotton padding for transferring pollen ${ }^{[95]}$ (Figure 6b). Experimental results show that the proposed system is able to achieve a $76.9 \%$ "pollination" success rate tested with high-fidelity artificial flowers ${ }^{[95]}$.

2.4.3 Selective working robots in livestock and poultry farming

In livestock and poultry farming, selective and targeted management are becoming more and more important, some prototypes in development are listed in Table 6. Automatic milking systems (AMS), when made mobile, give the possibility of milking cows in the field without additional labor ${ }^{[109]}$. In recent years, intelligent feeding control according to changes in behavior and growth status has gained increasing attention ${ }^{[55]}$. A lot of evisceration work to separate internal organs from poultry carcass is required in the poultry slaughtering industry, robotic eviscerating can ensure the safety of poultry processing health, improve the production efficiency and reduce labor intensity ${ }^{[110,111]}$. Infectious hoof disorders are a serious challenge for dairy productions since they cause pain and discomfort in cows and can compromise the competitiveness of dairy farming. Robot scrapers are capable of frequently removing liquid manure from slatted floors and can contribute to improved hygiene of walkways ${ }^{[112]}$.

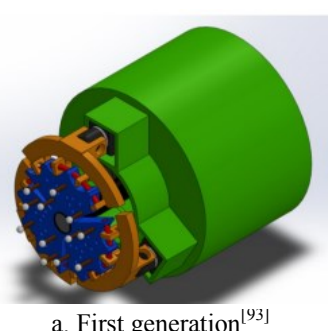

a. First generation ${ }^{[93]}$

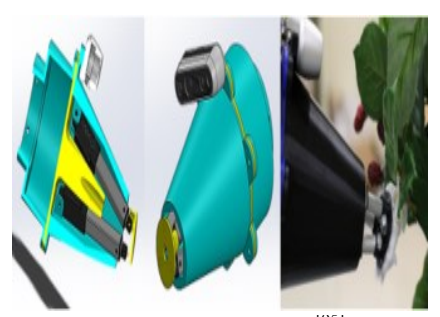

b. Second generation ${ }^{[95]}$
Figure 6 Pollinating end-effectors of BrambleBee

Table 6 Selective working robots in livestock and poultry farming

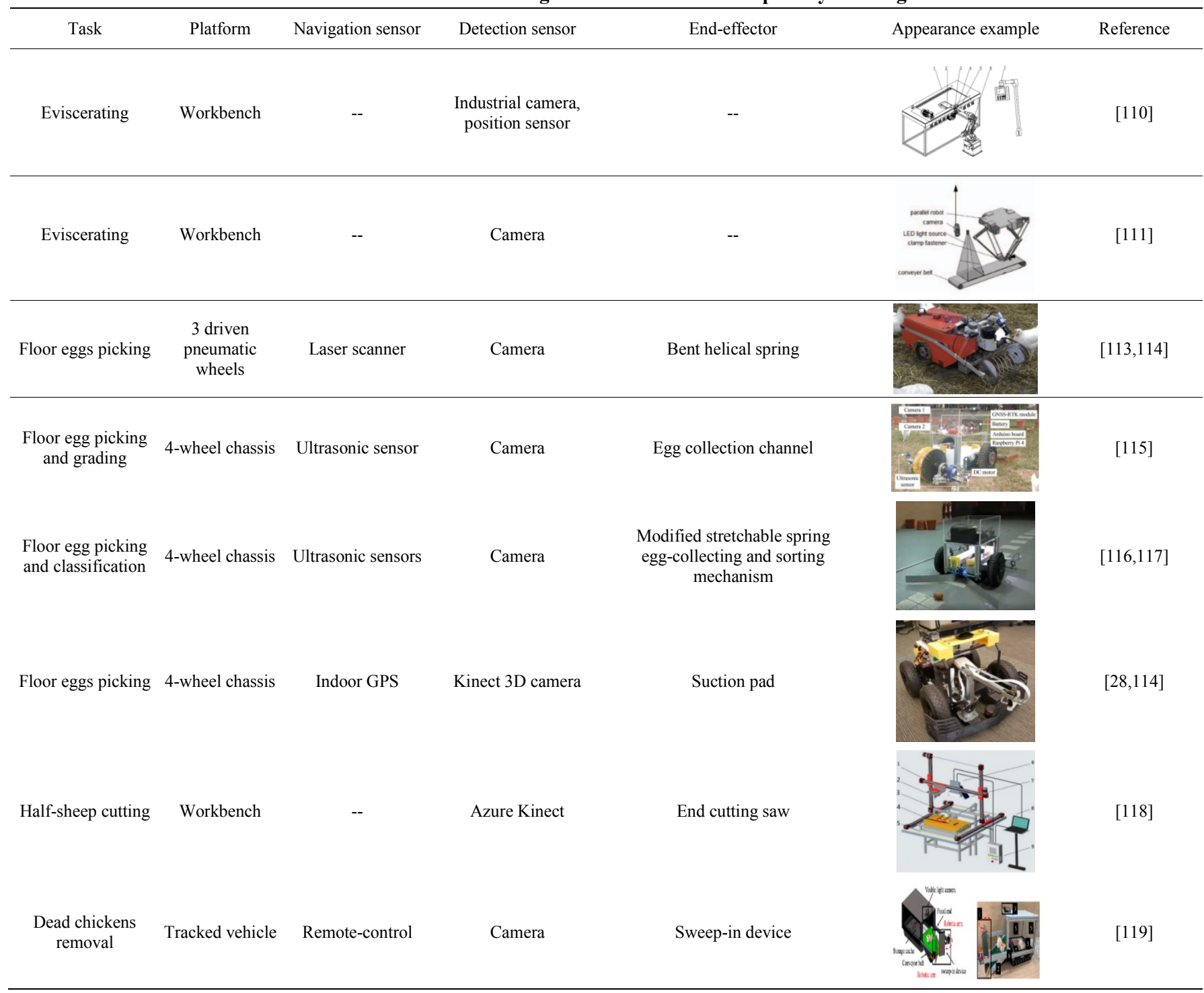


There is a growing interest in using automatic floor egg collection in the modern animal-friendly loose housing systems adopted for laying hens ${ }^{[113]}$. Bastiaan, Usher, Chang, et al have developed various prototypes of egg collection robots, some of them can realize egg picking and classification at the same time ${ }^{[28]}$. Poultrybot is a system in current development for automated floor-egg collection, in experiments, $46 \%$ of over 300 eggs were collected successfully ${ }^{[28,113-117]}$. The system developed by Joffe et al was retrofitted with a Microsoft Kinect 3D camera and a commercially available "indoor GPS" system, and the robust testing of the egg picking algorithms yielded a success rate of $91.6 \%{ }^{[28,117]}$.

\subsubsection{Commercial selective working robots}

Due to the non-structural and individual differences of the agricultural environment and crop object, the selective operation is a great challenge. However, more and more big companies invest in selective operational robot products development, more and more start-ups in this field are emerging and becoming industry stars. Bosch-funded start-up company Deepfield Robotics is the latest company to develop a field vehicle that can distinguish weeds from crops and neatly fish. Robots are used to fertilize the plants efficiently with a nitrogen fertilizer at the base of the crops. TerraSentia is the first robot from EarthSense, which can help crop breeders create new high-yielding crops with less water, chemicals, and other inputs. Harvest Croo Robotics in the United States and AgRobot in Spain are working with up to thirty picking parts based on visual detection, and even completing sorting and packaging simultaneously (Figure 7). The target herbicide spraying robot developed by Blue River Technology in the United States (Figure 8a), the weeding robot developed by $F$ Poulsen Company in Denmark (Figure 8b), and the lettuce thinning robot developed by Vision Robotics in the United States (Figure 8c), etc., carry out synchronous target spraying, weeding or thinning operations respectively with multiple working parts based on real-time visual detection or mapping. However, the large-scale commercialization of agricultural robots and their large-scale application in agricultural production still need time. The lack of supporting agronomy and the technical immaturity in the face of a complex agricultural environment are still the key obstacles.

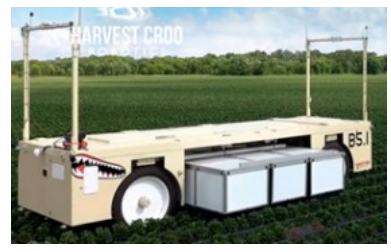

a. Harvest CROO

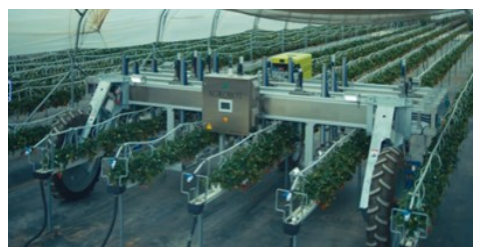

b. Agrobot
Figure 7 Large strawberry harvesting robot

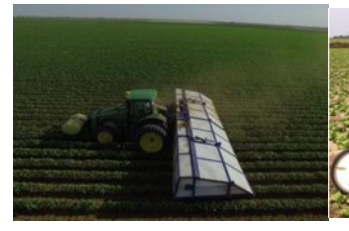

a. Blue River

Figure 8 Large field-managing robots

\section{Latest scientific and technical research}

\subsection{Scientific research}

Agricultural robots take the semi-natural ecosystem as the operating scene, the living body as the object, and the autonomous operation as the goal. They have the typical characteristics of being highly interdisciplinary. In particular, the breakthrough of selective working robot technology has put forward the objective requirements for basic scientific research of related disciplines and interdisciplinary research. On the contrary, the relevant basic research has also greatly enriched and promoted the development of agricultural robot technology.

3.1.1 Continuously deepening research on autonomous chassis and navigation

In agricultural application, the design and control of omnidirectional chassis and wheel-track combined chassis based on soil characteristics and ground mechanics of track slip and slippage is becoming a hot research topic. The navigation in greenhouses, orchards, tea gardens, livestock, poultry houses, and so on for robotic working usually bases on the full perception and understanding of local scene features, which is completely different from the motion-planning navigation in the open field based on satellite signal and global coordinates. The navigation technology based on agricultural scene perception has also been developed from relying on single information of $2 \mathrm{D}$ radar, CCD vision to RGB-D fusion. And this vision information is further integrated with obstacle judgement, geographical direction to realize deep understanding and comprehensive planning ${ }^{[120]}$. In addition, real-time sensing is furtherly being integrated with SLAM, field electronic mapping, IOT monitoring of agricultural conditions, etc. to put forward the deepening of scene-based navigation technology ${ }^{[121,122]}$.

3.1.2 Research on a damage-free robotic operation based on crop properties and robot-crop interaction

Selective harvesting is the largest application field of agricultural robots. An end-effector is the tool that directly interacts with the object and performs the operation task, its structure and principle are greatly different according to the crop, agricultural material properties and canopy structure, and its innovative research and development have also become the most active and productive direction of harvesting robot technology. Nowadays, the structure of chassis, vision system and manipulator are becoming more and more standardized, the end-effector has become the largest difference between different types of harvesting robot equipment.

At the same time, the agriculture robot must adjust the gripping force in real-time rather than exerting a predetermined force ${ }^{[123]}$. High-efficiency and damage-free are the core requirements of actual production for robotic operation in agriculture, but they are exactly contradictory. The study on the interaction rules of the fragile biological target and robot and behavior characteristics of harvesting robots are of great significance for realizing breakthrough of these requirements. The characterization of the viscoelastic-rheological constitutive models of various fruits has been studied all over the world. $\mathrm{Liu}^{[124]}, \mathrm{Ji}^{[125]}$ (Figure 9), Zhou ${ }^{[126]}, \mathrm{Li}^{[127]}$, et al., have successively carried out the modeling and simulation study of static gripping and dynamic collision between end-effector and viscoelastic fruit. Liu firstly established the research direction of high-speed damage-free harvesting and found two important characteristics of fast gripping collision: active energy input and constrained contact collision ${ }^{[124,128]}$. In addition, Xiong ${ }^{[129]}$, Bachche ${ }^{[130]}$, and $\mathrm{Liu}^{[131]}$, respectively researched the combined research of mechanical cutting, thermal cutting, laser cutting with the mechanics and heat transfer theory of fruit stem, petiole and weed.

3.1.3 Research on robot design and motion planning for agronomy-robot fusion

The research of agronomic-robot fusion has been paid more and more attention. Zhang et al. ${ }^{[132]}$ and Bac, et al. ${ }^{[133]}$ carried out 
research on the combination of cultivation pattern, crop canopy geometry, design and path planning of manipulator. Van Hock et al. ${ }^{[134]}$ designed varieties, climate, cultivation technology, light conditions for robot harvesting from the indices of visibility, reachability, grasp ability, and detectability. Bloch et al. ${ }^{[135]}$ presented and demonstrated a methodology for the simultaneous optimal design of robot kinematic and the working environment for robotic harvesting (Figure 10).
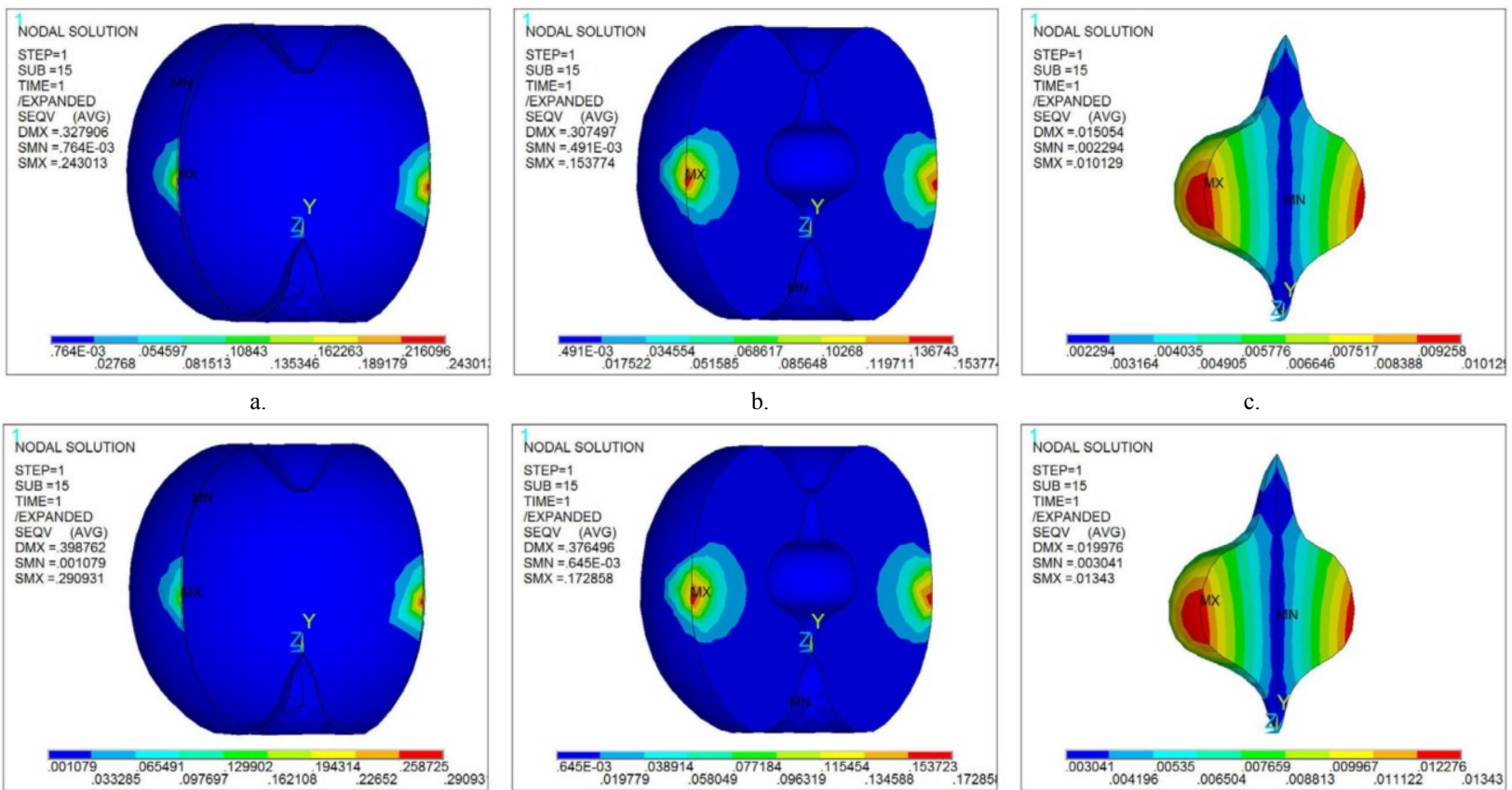

b.
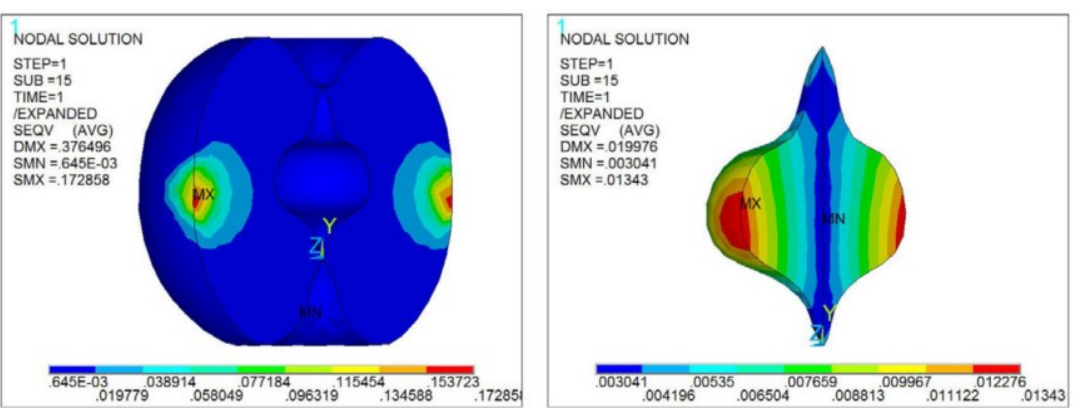

d.
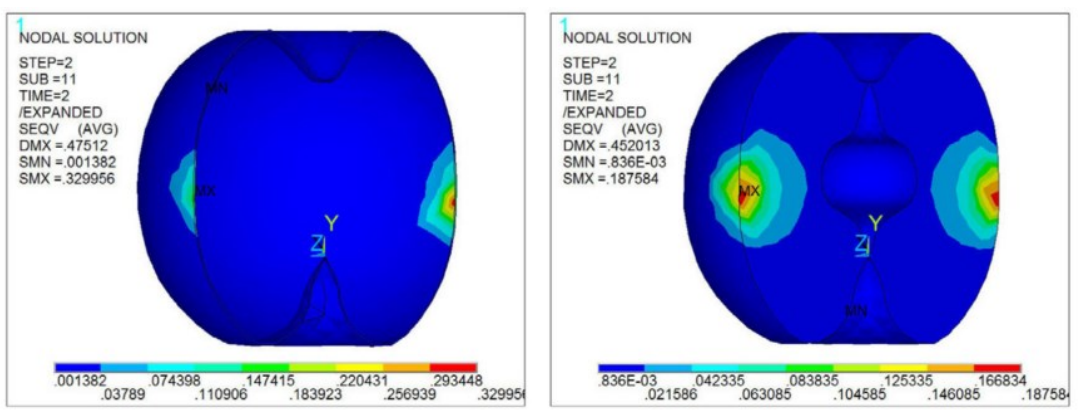

h.

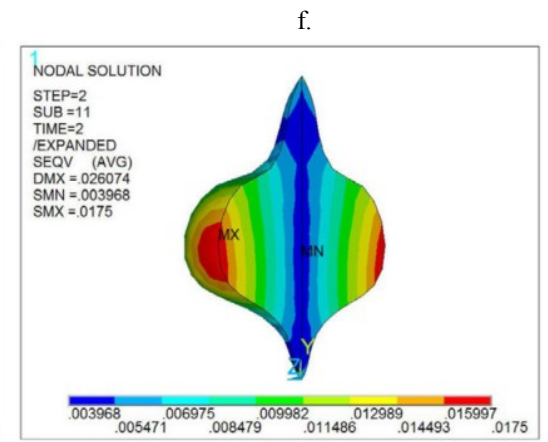

i.

Note: a, d, g are shown the maximum stress (SMX) and minimum stress (SMN) of apple skin at the grasping velocities of $0.1 \mathrm{~mm} / \mathrm{s}, 0.5 \mathrm{~mm} / \mathrm{s}, 1 \mathrm{~mm} / \mathrm{s}$, respectively; b, e h are shown the maximum stress (SMX) and minimum stress (SMN) of apple flesh at the grasping velocities of $0.1 \mathrm{~mm} / \mathrm{s}, 0.5 \mathrm{~mm} / \mathrm{s}, 1 \mathrm{~mm} / \mathrm{s}$, respectively; c, f, i are maximum stress (SMX) and minimum stress (SMN) of apple core at the grasping velocities of $0.1 \mathrm{~mm} / \mathrm{s}, 0.5 \mathrm{~mm} / \mathrm{s}, 1 \mathrm{~mm} / \mathrm{s}$, respectively.

Figure 9 Apple gripping stress distribution ${ }^{[125]}$
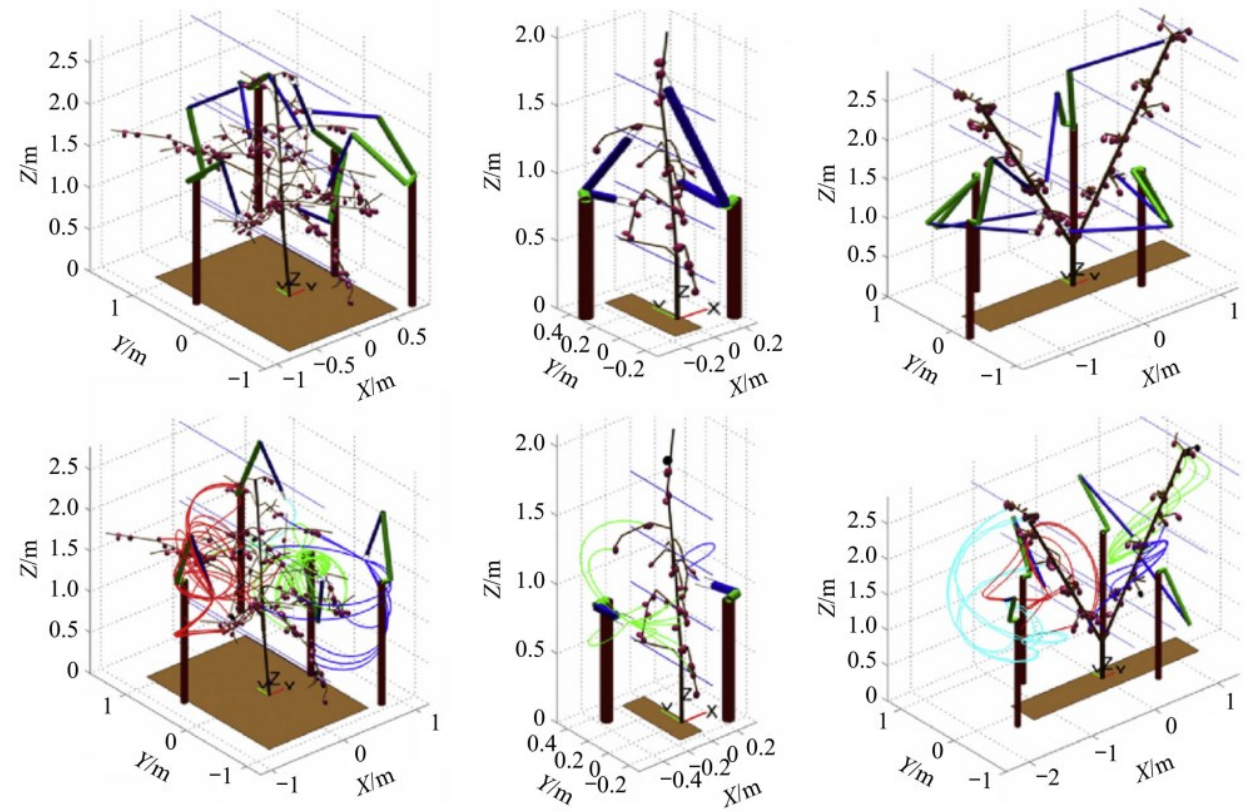

Figure 10 Optimal robots for different tree shapes ${ }^{[135]}$ 


\subsection{Technical research}

It can be found that virtual design technology, modular reconfigurable technology, bionic technology, etc. have been applied in the design of the whole machine and key components of agricultural robots. Especially, the innovative design of end-effector has become the concentrated application field of different kinds of new materials, new structures, and new technologies.

\subsubsection{Virtual robot-crop interaction technology}

Robot-crop interaction simulation can get rid of the limitations of the growing season, time and money costs of prototype development and experiments, and greatly accelerate the design, analysis and planning of the robot. Unlike the virtual and simulation design of traditional mechanical systems, virtual working simulation of agricultural robots relative to virtual fruit and vegetable targets in virtual scenes such as orchards has been continuously applied in robot research and development. A key step toward the acceleration of robotics is the choice of simulation software, middleware operating systems, and virtual environment platforms, and there is a long list of academic and professional simulation platforms that can be adapted and used for agricultural robots ${ }^{[136]}$. Mahmud et al. ${ }^{[137]}$ have carried out the design and planning of mobile robots under the virtual greenhouse crop environment. Zou et al. ${ }^{[138]}$ have carried out a simulation study on robotic harvesting in a virtual tree canopy environment.

\subsubsection{Robot reconfigurable technology}

A reconfigurable robot can change its configuration according to the change of task or environment. Grimstad et al. ${ }^{[139]}$ have developed the Thorvald II Robot, a reconfigurable multi-modularization agricultural mobile robot with power supply, drive, control, suspension, and detection. The EU Crops project has funded the research and development of modular reconfigurable agricultural robots which can realize the application of target spraying and harvesting tasks respectively ${ }^{[140]}$. Levin et al. ${ }^{[141]}$ have further established the design framework of a highly modular reconfigurable harvesting arm. Based on different tree shapes, different harvesting arm configurations can be reconstructed through the modular design of direct action, revolute joints, end-effectors, and connectors.

\subsubsection{Soft agricultural robot technology}

This research has become a hot topic and has great potential advantages in flexible and adaptive operations in agriculture. Mohamed et al. ${ }^{[142]}$ have developed a soft robotic arm that used agonist-antagonist actuators connected to the joints via flexible tendons for tomato harvesting. Using elastic silica gel as material, Bartlett et al. have designed a soft robotic hand with a pneumatic network as an actuator ${ }^{[143]}$. Devi et al. have developed an underactuated multi-finger soft robotic hand, whose bending joints adopted asymmetric bellow flexible pneumatic actuator (ABFPA), which could realize the dexterous grip of various geometric shapes ${ }^{[144]}$. Excell et al. have developed a six-finger soft picker, which can gently grasp fruits and vegetables according to their shapes ${ }^{[145]}$. Shea has applied a soft hand made of electroactive polymer actuator (EAP) to the gripping of tender fruits, showing the characteristics of fast and flexible $^{[146]}$ (Figure 11). Nishida et al. ${ }^{[147]}$ have developed a universal gripper using magnetorheological fluid (MR).

\subsubsection{Bionic design technology for agricultural robots}

Bionics design uses biological structure and functional principles to develop relevant equipment ${ }^{[148]}$, which is expected to provide an important opportunity for the development of agricultural robot technology. The joint and configuration design of six-legged agricultural robots has been carried out by Zhang ${ }^{[149]}$, Rong ${ }^{[150]}$ and Zhang $^{[151]}$. Huang et al. ${ }^{[152]}$ have designed a bio-inspired snake bone-armed robot for agricultural irrigation application. Li et al. ${ }^{[153]}$ have proposed an inchworm-like hook claw soft gripper actuated by shape memory alloy (SMA) spring. Quan ${ }^{[154]}$ has designed a multifunctional dragonfly claw-form bio-mimetic end-effector. Deng et al. ${ }^{[155]}$ have developed a bionic non-destructive handheld suction apple picker by combining handpicking action and octopus adsorption principle (Figure 12). Robotic bees for crop pollination promise to solve the growing problems of pollination quality caused by relying on natural bees ${ }^{[156]}$ (Figure 13).

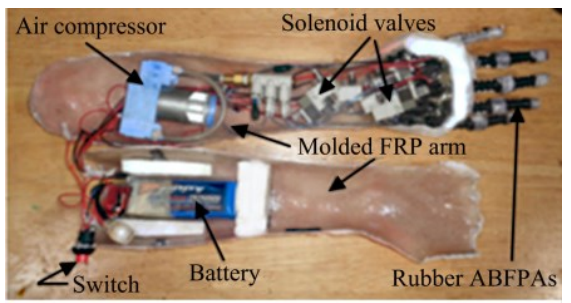

Figure 11 Multi-finger, multi-joint soft hand ${ }^{[146]}$
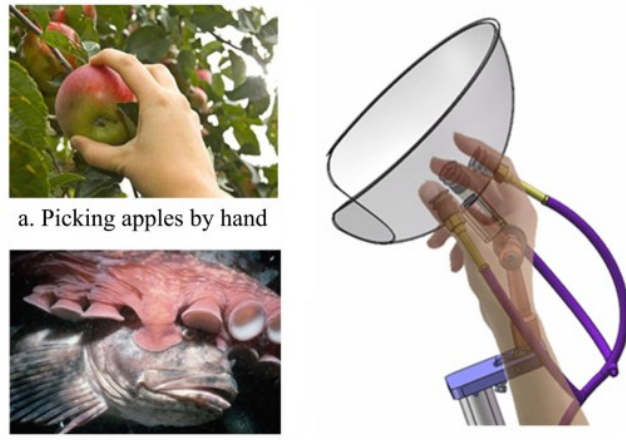

b. Octopuses hunt with suckers c. Simulating hand picking Figure 12 Bionic apple picking device ${ }^{[155]}$

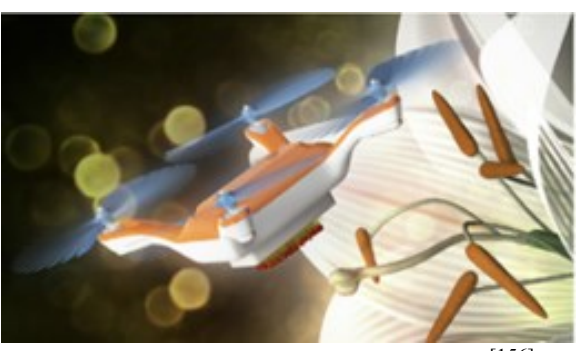

Figure 13 Robotic bee pollination ${ }^{[156]}$

3.2.5 Perception and understanding of decision-making techniques

It is the core of agricultural robots to realize the performance of autonomous working, and a lot of continuous research has been carried out in this field, which has strongly promoted the progress of this technology. As a long-term technical bottleneck of agricultural robot technology to the actual production, the rapid upgrading of hardware provides major support for the breakthrough of the technology: from black-and-white $\mathrm{CCD}$ to color $\mathrm{CCD}$, binocular-vision to highly integrated RGB-D camera supported by many source programs, high-speed GPU, and cloud-edge-terminal fusion computing system. At the same time, recognition and positioning technology methods are also developed from the traditional color image segmentation to multi-feature fusion and deep learning of deep image, RGB-D image. A major breakthrough is expected to make in visual recognition and positioning technology. The research based on combination sensing technologies of lidar, RGB-D, spectrum and UWB on fruit and vegetable target recognition and orchard navigation has been deepening ${ }^{[157-160]}$. The complex sense of touch and force based on 
piezoelectric film and electronic skin is greatly improving the ability to grasp delicate fruit and vegetable targets accurately and flexibly ${ }^{[161,162]}$ (Figure 14). At the same time, multi-information fusion, cross-media perception, deep learning, agricultural big data, cloud-edge-terminal fusion computing, multi-unit network cooperation, 5G communication and other technologies are promoting agricultural robots to achieve a leap from individually limited autonomous intelligence to unlimited full-process, full-chain, full-unmanned monitoring-working agriculture ${ }^{[163,164]}$ (Figures 15 and 16).

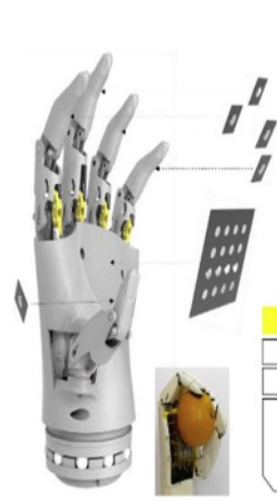

(a)

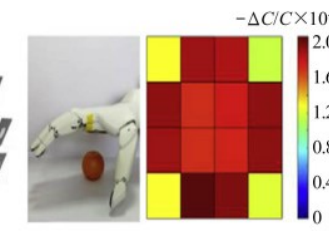

(b)

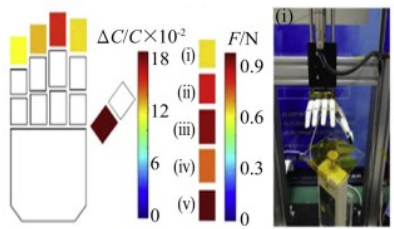

(d)

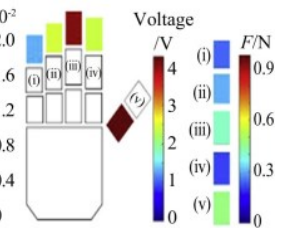

(c)

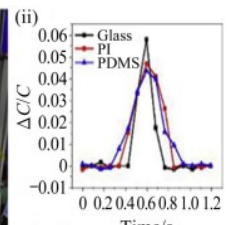

(e)

Note: (a) The integration of the sensor array in a bionic hand; (b) 3D shape mapping of an orange; (c) Open circuit voltage outputs of the fingertip sensor units during light grasping of the orange, the forces on each fingertip simultaneously measured by commercial thin-film sensors are shown on the right side; (d) Capacitance changes of fingertip sensors units during grasping the orange with higher pressure, simultaneous force measurements by commercial thin-film sensors are shown on the right side; (e) Hardness measurements using the E-skin on the bionic hand, experiment setup, (i) and capacitance changes as the bionic hand touched and retracted from three types of surfaces (ii).

Figure 14 Electronic skin ${ }^{[162]}$

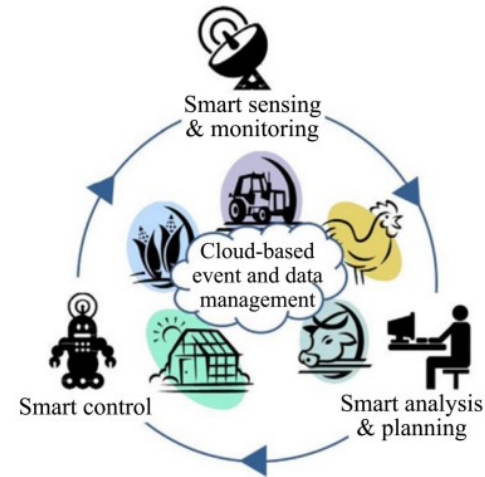

Figure 15 Intelligent agricultural monitoring-robotic working ${ }^{[163]}$

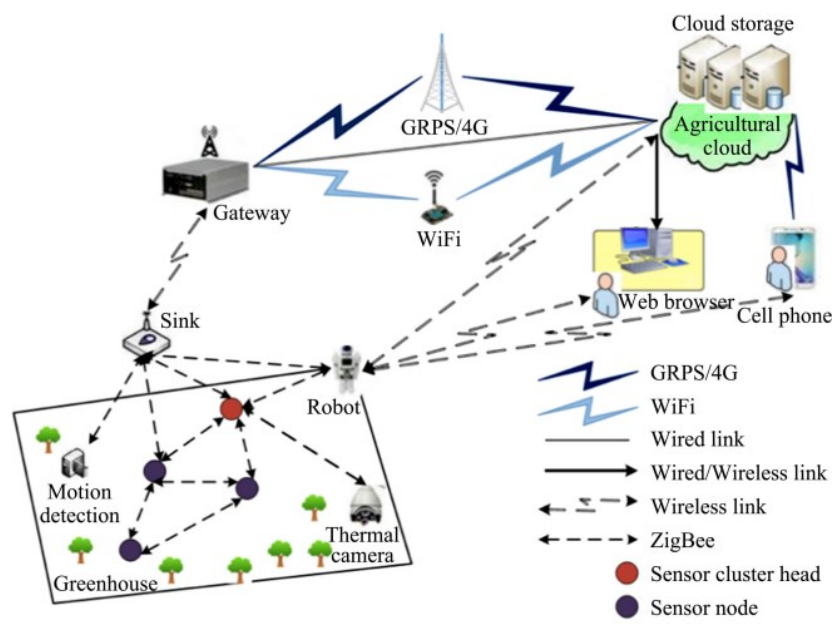

Figure 16 Agricultural cyber-physical fusion ${ }^{[164]}$

\section{Development of key agricultural robot technology}

\subsection{Key technologies for agricultural robots}

4.1.1 Fast damage-free operation technology

In either crop farming or livestock and poultry farming and aquaculture, autonomous operations for soil, water body and production facilities with water, fertilizer, or pesticide tend to be easier to implement. On the contrary, it is important and difficult to plant and harvest living crops, and catch animals, collect eggs or fish without damage. At the same time, fast or even high-speed operation makes the problem of damage more prominent, speedy damage-free operation is still a huge bottleneck of agricultural robots.

The realization of speedy damage-free operation, on the one hand, is largely determined by the innovative design of the end-effector supported by a new sensing method, new flexible material, new transmission structure. On the other hand, it depends on the effective dynamic soft gripping control and coordinated control of arm (manipulator)-hand (end-effector)-eye (vision) based on the mechanical-physiological properties of fruit-stem, etc.

4.1.2 Autonomous navigation technology for complex environment

The agricultural environment is regarded as a semi-natural environment, which has many random and seasonal components. For autonomous navigation under the conditions of open field, tea garden, orchard, vineyard, greenhouse, livestock and poultry, or water surface, there are great differences in scene features, navigation objectives and requirements, and information sources. At present, the navigation is mainly divided into global navigation based on world coordinates and local navigation based on scene perception, and there is also a huge difference between indoor and outdoor navigation. Global navigation based on satellite signals has been widely used in agricultural machinery operation, but the local navigation in so complicated and different agricultural scene is still a certain distance from production. Furtherly, according to the actual production needs, global-local, indoor-outdoor integrated navigation in more environments is becoming the focus and key.

4.1.3 Target detection technology for complex backgrounds

Vision technology is the core of agricultural robot technology, and undoubtedly, it is also the biggest bottleneck in the application and promotion of agricultural robot technology so far. Harvesting robots need to guarantee the fruit of the reliable detection and positioning of target fruit in complex dense canopy, weeding robot needs to distinguish between crops and weeds reliably within the complex soil backgrounds. Compare with industrial applications, all the above backgrounds are unstructured, highly random and changeable. Until today, these visual tasks are still a huge challenge. Traditional image segmentation technology relying on color difference features has been proved its huge limitations. Be competent for such a complex task, different features from depth image, thermal image, spectral image, etc, may be helpful to fuse with RGB image. The breakthrough of target detection technology for complex backgrounds needs to realize the important breakthrough of multi-information fusion technology and image processing algorithm under the guarantee of rapid upgrading of vision hardware (sensors, chips).

\subsubsection{Special design technology for agricultural robots}

Today, for the design of traditional industrial robots, there are typical methods, standards, and tools. However, the working environment, object, and task of agricultural robots are so different from those of industrial robots, their design is also more 
complicated than and much different from the existing technology of industrial robots. Therefore, it is the objective need of the development of technology and industry to establish the special design system of agricultural robots through the joint efforts of academia and the industry. Today, there has been a good academic exploration, but the special design methods, design techniques, design tools still need to be established.

\subsection{Path to realize the breakthrough of key technologies}

4.2.1 Modelling and virtual simulation of robot-crop interaction

At present, great progress has been made in the 3D modeling and virtual simulation of agricultural robots, as well as in the virtual simulation and analysis of robot-crop integration. However, the existing simulation of robot crop interaction is still limited to size matching and operation observation, and the soft handling simulation of end-effector to fruit target is not integrated with the whole robot and working environment. One day virtual reality will be integrated with mechanical-physical physiological-interaction of robot-crop, with visual detectability and hand-arm maneuverability, with crop phenotypes and robot digital design. Virtual reality based on deep robot-crop interaction will promote the research of design, navigation, perception and fast damage-free operation control of agricultural robots.

\subsubsection{Comprehensive support of big data}

Today, agricultural robots have moved forward from single machine optimization to big data supported design, perception control and collaboration. By establishing database and systematic data mining methods of knowledge big data, agricultural big data, industry chain big data, the design, manufacturing, sensing and control optimization, the application will be greatly accelerated. Construction and reasoning of agricultural robot technology efficacy map based on patent knowledge graph will realize the rapid digital design for the specific environment, objects and tasks and reduce the challenge and risk of innovative design. Industrial chain big data will connect the upstream and downstream relationship of the agricultural robots industry, and provide strong support for the special modularization and small-batch customization of agricultural robots. Big data of patrol inspection and internet of things (IoT) of agricultural production will realize continuous training of models and algorithms, and make it possible for agricultural robots to realize robust autonomous operation without intervention in the whole process.

\subsubsection{Comprehensive support of artificial intelligence}

Today, artificial intelligence has been fully integrated into all fields of production and life. From different types of equipment of mobile phones, automobiles, public transportation, engineering vehicles to different fields of entertainment, tourism, shopping, education and manufacturing, artificial intelligence is playing a more and more important role. The rapid development of key technologies of driverless with artificial intelligence as the core, vision and key components of solid-state lidar, supercomputing chips will inject strong power into the development of agricultural robot technology. Agricultural robot technology will be fully supported and empowered by artificial intelligence, supported by $5 \mathrm{G}$ communication technology and large computing power chip technology. Agricultural robots can perform big data acquisition and autonomous operation tasks in agricultural scenes, while artificial intelligence can enhance the fusion and understanding ability of big data and the interaction ability of robots. Through deep learning, cloud edge fusion computing, adaptive learning, cross-media computing, etc., agricultural robot technology will accelerate its performance improvement and continuously shorten its $\mathrm{R} \& \mathrm{D}$ cycle. Artificial intelligence in combination with agriculture robots will make a great breakthrough in agriculture.

\section{Acknowledgements}

The research was supported by grants from the National Natural Science Foundation of China (Grant No. 31971795), Project of Faculty of Agricultural Equipment of Jiangsu University (Grant No. 4111680002) and A Project Funded by the Priority Academic Program Development of Jiangsu Higher Education Institutions (No. PAPD-2018-87).

\section{[References]}

[1] Oliveira L, Moreira A P, Silva M F. Advances in agriculture robotics: A state-of-the-art review and challenges ahead. Robotics, 2021; 10(2): 52 doi: 10.3390/robotics 10020052

[2] Saiz V, Rovira F. From smart farming towards agriculture 5.0: A review on crop data management. Agronomy, 2020; 10(2): 207. doi: 10.3390/ agronomy10020207.

[3] Palli P, Liew C T, Drozda A, Mwunguzi H, Pitla S K, Walia H, et al. Robotic gantry for automated imaging, sensing, crop input application, and high-throughput analysis. In: 2019 ASABE Annual International Meeting, ASABE, 2019; Paper number: 1901519. doi: 10.13031/aim.201901519.

[4] Hang L, Tang L, Steven W, Mei Y. A robotic platform for corn seedling morphological traits characterization. Sensors, 2017; 17(9): 2082. doi: 10.3390/s17092082.

[5] Xie Z J, Gu S, Chu Q, Li B, Fan K J, Yang Y L, et al. Development of a high-productivity grafting robot for Solanaceae. Int J Agric \& Biol Eng, 2020; 13(1): 82-90.

[6] Jiang K, Zhang Q, Chen L P, Guo W Z, Zheng W G. Design and optimization on rootstock cutting mechanism of grafting robot for cucurbit Int J Agric \& Biol Eng, 2020; 13(5): 117-124.

[7] Treiber M, Hillerbrand F, Bauerdick J, Bernhardt H. On the current state of agricultural robotics in crop farming - chances and risks. In: 47th Int Symposium "Actual Tasks Agr Eng", Croatia, 2019; pp.27-33.

[8] Scholz C, Moeller K, Ruckelshausen A, Hinck S, Goettinger, M. Automatic soil penetrometer measurements and gis-based documentation with the autonomous field robot platform bonirob. 12th Int Conf Precision Agr, 2014.

[9] Saiz V, Rovira F, Millot C. Performance improvement of a vineyard robot through its mechanical design. In: 2017 ASABE Annual International Meeting, 2017; Paper number: 1701120. doi: 10.13031/ aim. 201701120 .

[10] Annalisa M, Giulio R, Michael N. A multi-sensor robotic platform for ground mapping and estimation beyond the visible spectrum. Precision Agriculture, 2018; 20(2): 423-444.

[11] Xu E, Hou B M, JiaNa B I, Shen Z G, Wang B. Smart agriculture based on internet of things. In: 2nd Int Conf Robotics, Electr \& Signal Process Tech, 2021; pp.157-162. doi: 10.1049/et.2014.0926.

[12] Bayati M, Fotouhi R. A mobile robotic platform for crop monitoring. Advances in Robotics \& Automation, 2018; 7(1): 1000186. doi: 10.4172/2168-9695.1000186

[13] Dos Santos Xaud M F, Leite A C, Barbosa E S, Faria H D, Loureiro G, From P J. Robotic tankette for intelligent bioenergy agriculture: design, development and field tests. XXII Congresso Brasileiro de Automatica (CBA2018). Joao Pessoa, Brazil, 2018; 1357. doi 10.20906/CPS/CBA2018-1357.

[14] Dos Santos F N, Sobreira H M P, Campos D F B, Morais R, Moreira A P G M, Contente O M S. Towards a reliable monitoring robot for mountain vineyards. In: 2015 IEEE International Conference on Autonomous Robot Systems and Competitions. Vila Real, Potugal: IEEE, 2015; pp.37-43. doi: 10.1109/ICARSC.2015.21.

[15] Gupta G S, Seelye M, Seelye J, Bailey D. Autonomous anthropomorphic robotic system with low-cost colour sensors to monitor plant growth in a laboratory. In-Tech, 2012; 22p.

[16] Ota T, Iwasaki Y, Nakano A, Kuribara H, Higashide T. Development of yield and harvesting time monitoring system for tomato greenhouse production. Eng in Agr, 2018; 12(1): 41-47.

[17] Rizk H, Habib M K. Robotized early plant health monitoring system. In: IECON 2018 - 44th Annual Conference of the IEEE Industrial 
Electronics Society. Washington, DC: IEEE, 2018; pp.3795-3800. doi: 10.1109/IECON.2018.8592833

[18] Vidoni R, Gallo R, Ristorto G, Carabin G, Mazzetto F, Scalera L, et al. ByeLab: An agricultural mobile robot prototype for proximal sensing and precision farming. In: ASME International Mechanical Engineering Congress \& Exposition, 2017; Paper No. IMECE2017-71216, V04AT05A057. doi: 10.1115/IMECE2017-71216.

[19] Bietresato M, Carabin G, Auria D, Gallo R, Ristorto G, Mazzetto F, et.al. A tracked mobile robotic lab for monitoring the plants volume and health. In: 2016 12th IEEE/ASME Int Conf on Mechatronic and Embedded Systems and Applications (MESA). Auckland: IEEE, 2016; pp.1-6. doi: 10.1109/MESA.2016.7587134.

[20] Ahmadi A, Nardi L, Chebrolu N, Stachniss C. Visual servoing-based navigation for monitoring row-crop fields. In: 2020 IEEE Int Conf on Robotics and Automation (ICRA). IEEE, 2020; pp.4920-4926. https://arxiv.org/abs/1909.12754.

[21] Ollero A, Sanfeliu A, Montano L, Lau N, Cardeira C. Grape: ground robot for vineyard monitoring and protection. Third Iberian Robotics Conf, 2017; pp.249-260. doi: 10.1007/978-3-319-70833-1 21.

[22] Rey B, Aleixos N, Cubero S, Blasco J. Xf-Rovim. A field robot to detect olive trees infected by Xylella fastidiosa using proximal sensing. Remote Sensing, 2019; 11(3): 221. doi: 10.3390/rs11030221.

[23] Cubero S, MarcoNoales E, Aleixos N, Barbé S, Blasco J. Robhortic: A field robot to detect pests and diseases in horticultural crops by proximal sensing. Agriculture, 2020; 10(7): 276 . doi: 10.3390/ agriculture10070276.

[24] Roviramás F, Millot C, Sáizrubio V. Navigation strategies for a vineyard robot. In: 2015 ASABE Annual International Meeting, 2015; Paper number: 152189450 . doi: 10.13031/aim.20152189750.

[25] Schmitz A. Row crop navigation by autonomous ground vehicle for crop scouting. Doctoral dissertation. Manhattan: Kansas State University, 2017; 86p.

[26] Mancini A, Frontoni E, Zingaretti P. Satellite and uav data for precision agriculture applications. Int Conf on Unmanned Aircraft Syst (ICUAS), 2019; pp.491-497. doi: 10.1109/ICUAS.2019.8797930

[27] Liebisch F, Pfeifer J, Khana R, Lottes P, Stachniss C, Falck T. Flourish-A robotic approach for automation in crop management. 14th International Conference on Precision Agriculture, Quebec, 2018; Available: $\quad$ https://www.researchgate.net/publication/301921276. Accessed on [2021-7-29]

[28] Usher C T, Daley W D, Joffe B P, Muni A. Robotics for poultry house management. In: 2017 ASABE Annual International Meeting, 2017; 1701103. doi: 10.13031/aim.201701103.

[29] EsnaolaGonzalez I, Gomez M, Ferreiro S, Fernandez I, Garcia E. An IoT platform towards the enhancement of poultry production chains. Sensors, 2020; 20(6): 1549. doi: 10.3390/s20061549.

[30] Qi H X, Banhazi T M, Zhang Z G, Low T, Brookshaw I J. Preliminary laboratory test on navigation accuracy of an autonomous robot for measuring air quality in livestock buildings. Int J Agric \& Biol Eng, 2016; 9(2): 29-39.

[31] Mayer K, Ellis K, Taylor K. Cattle health monitoring using wireless sensor networks. In: Proc of the Communication and Comput Networks Conference, 2004; pp. 8-10.

[32] Pastell M, Aisla A M, Hautala M, Ahokas J, Veermäe I. Automatic cow health measurement system in a milking robot. In: 2006 ASAE Annual Meeting, 2006; Paper number 064037. doi: 10.13031/ 2013.20915.

[33] Pastell M, Takko H, Hautala M, Poikalainen V, Praks J, Veermäe I, et al. Monitoring cow health in a milking robot. Precision Livestock Farming, 2005; 5: 187-192.

[34] McMeniman J. Prototype feedlot autonomous mobile robot for bunk calling. Meat \& Livestock Australia Limited ABN, 2019; 13p.

[35] Luna F, Aguilar E, Naranjo J S, Jagüey J G. Robotic system for automation of water quality monitoring and feeding in aquaculture shadehouse. IEEE Transactions on Systems, Man, and Cybernetics: Systems, 2017; 47(7): 1575-1589.

[36] Huang L W, Li Z W, Li S R, Liu L, Shi Y G. Design and application of a free and lightweight aquaculture water quality detection robot. $\mathrm{J}$ Européen des Systèmes Automatisés, 2020; 53(1): 111-122.

[37] Borstel F V, Suárez J, Edgar D, Gutiérrez J. Feeding and water monitoring robot in aquaculture greenhouse. Industrial Robot, 2013; 40(1): 10-19.

[38] Livanos G, Zervakis M, Chalkiadakis V, Moirogiorgou K, Papandroulakis $\mathrm{N}$. Intelligent navigation and control of a prototype autonomous underwater vehicle for automated inspection of aquaculture net pen cages In: 2018 IEEE International Conference on Imaging Systems and Techniques. Krakow, Poland: IEEE, 2018; pp.1-6. doi: 10.1109/ IST.2018.8577180.

[39] Huang L W, Li Z W, Li S, Liu L, Shi Y G. Design and application of a free and lightweight aquaculture water quality detection robot. J Européen des Systèmes Automatisés, 2020; 53(1): 111-122.

[40] Wang K S, Huang C K. Intelligent robotic lawn mower design. In 2018 International Conference on System Science and Engineering (ICSSE), 2018; pp.1-5. doi: 10.1109/ICSSE.2018.8520053.

[41] Ibrahim B, Brahmaiah V S, Sharma P. Design of smart autonomous remote monitored solar powered lawnmower robot. Materials Today: Proceedings, 2020; 28: 2338-2344. doi: 10.1016/j.matpr.2020.04.633.

[42] Chung C H, Wang K C, Liu K T, Wu Y T, Lin C C, Chang C Y. Path planning algorithm for robotic lawnmower using RTK-GPS localization. International Symposium Community-centric Systems (CcS). Tokyo: IEEE, 2020; pp.1-4. doi: 10.1109/CcS49175.2020.9231484.

[43] Daniyan I, Balogun V, Adeodu A, Oladapo B, Peter J K, Mpofu K Development and performance evaluation of a robot for lawn mowing. Procedia Manufacturing, 2020; 49: 42-48. doi: 10.1016/ j.promfg.2020.06.009.

[44] Opiyo S, Okinda C, Zhou J, Mwangi E, Makange N. Medial axis-based machine-vision system for orchard robot navigation. Computers and Electronics in Agriculture, 2021; 185: 106153. doi: 10.1016/ j.compag.2021.106153.

[45] Peng W, Pengbo W, Changxing G. A combined visual navigation method for greenhouse spray robot. In: 2019 IEEE 9th Annual International Conference on CYBER Technology in Automation, Control and Intelligent Systems (CYBER), IEEE, 2019; pp.604-608. doi 10.1109/CYBER46603.2019.9066557.

[46] Cariou C, Roux J C, Lenain R. Laser beam deflection of a 2D LiDAR for canopy detection on an autonomous spraying robot. In: 2021 7th International Conference on Automation, Robotics and Applications (ICARA), IEEE, 2021; pp.80-84. doi: 10.1109/ICARA51699.2021. 9376553.

[47] Liu J Z, Zhao S Y, Li N, Faheem M, Zhou T, Cai W J, et al. Development and field test of an autonomous strawberry plug seeding transplanter for use in elevated cultivation. Applied Engineering in Agriculture, 2019; 35(6): 1067-1078. doi: 10.13031/aea.13236.

[48] Liu J Z, Peng H J, Li N, Jiang S J, Ju J. Design and experiments of automatic mobile substrate paver for elevated cultivation. Transactions of the CSAM, 2018; 49(1): 58-67. (in Chinese)

[49] Ju J, Liu J Z, Li N, Li P P. Curb-following detection and navigation of greenhouse vehicle based on arc array of photoelectric switches. Transactions of the CSAE, 2017; 33(18): 180-187. (in Chinese)

[50] Zhou T. Research and experiment of high-ridge automatic transplanter for double-row strawberry plug seedlings. Master dissertation. Zhenjiang: Jiangsu University, 2019; 79p. (in Chinese)

[51] Feng Q, Wang X. Design of disinfection robot for livestock breeding. Procedia Computer Science, 2020; 166: 310-314.

[52] Feng Q C, Wang X, Qiu Q, Zhang C F, Li B, Xu R F, et al. Design and test of disinfection robot for livestock and poultry house. Smart Agriculture, 2020; 2(4): 79-88. (in Chinese)

[53] House H, Eng P. Manure handling options for robotic milking barns. Dairy Housing, 2016; pp.1-8.

[54] Hou Y T, Yao L H, Cai X H, Wang Q. Research and realization of automatic barn cleaner path planning. Journal of Agricultural Mechanization Research, 2017; 39(6): 23-26. (in Chinese)

[55] Zhou C, Xu D M, Lin K, Sun C H, Yang X T. Intelligent feeding control methods in aquaculture with an emphasis on fish: A review. Reviews in Aquaculture, 2018; 10(4): 975-993.

[56] Ruan C Z, Zhao D A, Sun Y P, Hong J Q, Ding S H, Luo J. Design and testing of a control system associated with the automatic feeding boat for farming Chinese river crabs. Computers \& Electronics Agriculture, 2018; 150: $14-25$.

[57] Sun Y P, Zhao D A, Hong J Q, Zhang J, Li F Z. Design of automatic and uniform feeding system carried by workboat and effect test for raising river crab. Transactions of the CSAE, 2015; 31(11): 31-39. (in Chinese)

[58] Pribadi W, Prasetyo Y, Juliando D E. Design of fish feeder robot based on arduino-android with fuzzy logic controller. Int. Res. J. Adv. Eng. Sci, 2020; 5(4): 47-50.

[59] Hu Y B, Ni Q, Huang D, Li J G. Analysis on the positioning accuracy of fishpond cleaning robot in industrial aquaculture. Fishery Modernization, 
2021; 48(2): 16-21, 28. (in Chinese)

[60] Kaizu Y, Shimada T, Takahashi Y, Igarashi S, Yamada H, Furuhashi K, et al. Development of a small electric robot boat for mowing aquatic weeds. Transactions of the ASABE, 2021; 64(3): 1073-1082.

[61] Strisciuglio N, Tylecek R, Blaich M, Petkov N, Biber, P, et al. Trimbot2020: An outdoor robot for automatic gardening. In: 50th Int Symp Robotics., 2018; pp.1-6.

[62] Silwal A, Davidson J R, Karkee M, Mo C, Zhang Q, Lewis K. Design, integration, and field evaluation of a robotic apple harvester. Journal of Field Robotics, 2017; 34(2): 1140-1159. doi: 10.1002/rob.21715.

[63] Li T, Qiu Q, Zhao C J, Xie F. Task planning of multi-arm harvesting robots for high-density dwarf orchard. Transactions of the CSAE, 2021; 37(2): 1-10. (in Chinese)

[64] Williams H, Ting C, Nejati M, Jones M H, Penhall N, Lim J Y, et al. Improvements to and large-scale evaluation of a robotic kiwifruit harvester. Journal of Field Robotics, 2020; 37(2): 187-201.

[65] Williams H A M, Jones M H, Nejati M, Seabright M J, Bell J, Penhal N D, et al. Robotic kiwifruit harvesting using machine vision, convolutional neural networks, and robotic arms. Biosystems Engineering, 2019; 181: $140-156$.

[66] Zhang S S. Control method of dual arm picking robot for kiwifruit. Master dissertation. Yangling: Northwest A\&F University, 2018; 106p. (in Chinese)

[67] Mu L T, Cui G P, Liu Y D, Cui Y J, Fu L S, Gejima Y. Design and simulation of an integrated end-effector for picking kiwifruit by robot. Information Processing in Agriculture, 2020; 7(1): 58-71.

[68] SepúLveda D, Fernández R, Navas E, Armada M, GonzálezDeSantos P. Robotic aubergine harvesting using dual-arm manipulation. IEEE Access, 2020; 8: 121889-121904.

[69] Peng Y, Liu J, He M, Shan H, Xie B, Hou G Y, et al. Research progress of urban dual-arm humanoid grape harvesting robot. In: 2021 Cyber IEEE Int Conf, 2021; Paper number: 459.

[70] Chen X, Chaudhary K, Tanaka Y, Nagahama K, Yaguchi H, Okada K, et al. Reasoning-based vision recognition for agricultural humanoid robot toward tomato harvesting. In: 2015 IEEE/RSJ International Conference on Intelligent Robots and Systems (IROS). Hamburg, Germany: IEEE, 2015; pp.6487-6494. doi: 10.1109/IROS.2015.7354304.

[71] Zion B, Mann M, Levin D, Shilo A, Rubinstein D, Shmulevich I. Harvest-order planning for a multiarm robotic harvester. Computers \& Electronics in Agriculture, 2014; 103: 75-81.

[72] Mann M P, Zion B, Shmulevich I, Rubinstein D, Linker R. Combinatorial optimization and performance analysis of a multi-arm cartesian robotic fruit harvester-extensions of graph coloring. $\mathrm{J}$ of Intell \& Robotic Syst, 2016; 82(3-4): 399-411.

[73] Liu X K, Li B, Chang J, Zhang G W, Wang C. Structure design and analysis of wolfberry picking robot's dual manipulator. Chinese High Technology Letters, 2019; 29(2): 175-182. (in Chinese)

[74] Davidson J R, Hohimer C J, Mo C, Karkee M. Dual robot coordination for apple harvesting. In: 2017 ASABE Annual International Meeting, Spokane, WA: ASABE, 2017; Paper number: 1700567. doi: 10.13031/ aim.201700567.

[75] Zhao Y, Gong L, Liu C, Huan, Y. Dual-arm robot design and testing for harvesting tomato in greenhouse. IFAC-Papers OnLine, 2016; 49(16): $161-165$.

[76] Ling X, Zhao Y S, Gong L, Liu C L, Wang T. Dual-arm cooperation and implementing for robotic harvesting tomato using binocular vision. Robotics \& Autonomous Systems, 2019; 114: 134-143.

[77] Santhi P V, Kapileswar N, Chenchela V K, Prasad C V S. Sensor and vision based autonomous AGRIBOT for sowing seeds. In: 2017 International Conference on Energy, Communication, Data Analytics \& Soft Computing (ICECDS). Chennai, India: IEEE, 2017; pp.242-245. doi: 10.1109/ICECDS.2017.8389873.

[78] Zhou X. Design and tests of intelligent sorting-transplanting-replanting integrated machine for plug seedlings in greenhouse. Master dissertation. Zhenjiang: Jiangsu University, 2019; 141p. (in Chinese)

[79] Danton A, Roux J C, Dance B, Cariou C, Lenain R. Development of a spraying robot for precision Agr: An edge following approach. In: 2020 IEEE Conference Control Technology \& Applications (CCTA), 2020; pp.267-272. doi: 10.1109/CCTA41146.2020.9206304.

[80] Cantelli L, Bonaccorso F, Longo D, Melita C D, Schillaci G, Muscato G. A small versatile electrical robot for autonomous spraying in agriculture. AgriEngineering, 2019; 1(3): 391-402.

[81] Reiser D, Sehsah E S, Bumann O, Morhard J, Griepentrog H W.
Development of an autonomous electric robot implement for intra-row weeding in vineyards. Agriculture, 2019; 9(1): 18. doi: 10.3390/ agriculture9010018.

[82] Katyara S, Ficuciello F, Caldwell D G, Chen F, Siciliano B Reproducible pruning system on dynamic natural plants for field agricultural robots. In: Human-Friendly Robotics 2020, 13th International Workshop, 2020; pp. 1-15. doi: 10.1007/978-3-03071356-0 1.

[83] You A, Sukkar F, Fitch R, Karkee M, Davidson J R. An efficient planning and control framework for pruning fruit trees. In: 2020 IEEE International Conference on Robotics \& Automation (ICRA). Paris: IEEE, 2020; pp.3930-3936. doi: 10.1109/ICRA40945.2020.9197551.

[84] Kaljaca D, Vroegindeweij B, Van Henten E. Coverage trajectory planning for a bush trimming robot arm. J Field Robotics, 2020; 37(2): 283-308.

[85] Polishchuk M, Tkach M, Parkhomey I, Boiko J, Eromenko O. Walking mobile robot for trimming trees: design and modeling. International J Control \& Autom, 2020; 13(2): 1760-1772.

[86] Van Tuijl B A J, Tielen A P M, Mencarelli A, Hemming J. Structured design of a novel end-effector for a bush trimming robot. Proc European Conf Agr Eng, 2018; pp.188-196.

[87] Kondo N, Monta M, Shibano Y. Multi-operation robot for fruit production. In: Proc Korean Soc Agr Mach Conf, 1996; pp. 621-631.

[88] Lyons D J, Heinemann P H, Schupp J R, Baugher T A, Liu J. Development of a selective automated blossom thinning system for peaches. Transactions of the ASABE, 2015; 58(6): 1447-1457. doi: 10.13031/trans.58.11138.

[89] Zhang K, Zhao L N, Zhe S, Geng C X, Li W. Design and experiment of intelligent grape bagging robot. Appl Mech \& Mater., 2013; 389: 706-711. doi: 10.4028/www.scientific.net/AMM.389.706.

[90] Monta M, Kondo N, Shibano Y, Mohri K. End-effectors for agricultura robot to work in vineyard. Greenhouse Environ Control \& Autom, 1994; 399: 247-254

[91] Van Henten E J, Van Tuijl B A J, Hoogakker G J, Van Der Weerd M. J, Hemming J, Kornet $\mathrm{J}$ G, et al. An autonomous robot for de-leafing cucumber plants grown in a high-wire cultivation system. Biosystems Engineering, 2006; 94(3): 317-323

[92] Ota T, Bontsema J, Hayashi S, Kubota K, Van Henten E J, Can Os E A, et al. Development of a cucumber leaf picking device for greenhouse production. Biosystems Engineering, 2007; 98(4): 381-390.

[93] Ohi N, Lassak K, Watson R, Strader J, Du Y, Li W. Design of an autonomous precision pollination robot. In: 2018 IEEE/RSJ International Conference on Intelligent Robots \& Systems (IROS). Madrid: IEEE, 2018; pp.7711-7718. doi: 10.1109/IROS.2018.8594444.

[94] Yuan T, Zhang S, Sheng X, Wang D, Gong Y, et al. An autonomous pollination robot for hormone treatment of tomato flower in greenhouse. 3rd Int Conf Syst \& Inform (ICSAI). IEEE, 2016; pp.108-113. doi: 10.1109/ICSAI.2016.7810939.

[95] Strader J, Nguyen J, Tatsch C, Du Y X, Lassak K, Buzzo B, et al Flower interaction subsystem for a precision pollination robot. In: 2019 IEEE/RSJ Int Conf Intell Robots \& Syst (IROS), 2019; pp. 5534-5541.

[96] Williams H, Nejati M, Hussein S, Penhall N, Lim J Y, Jones M H, et al Autonomous pollination of individual kiwifruit flowers: Toward a robotic kiwifruit pollinator. J Field Robotics, 2020; 37(2): 246-262.

[97] Barnett J, Seabright M, Williams H A, Nejati M, Scarfe A J, Bell J, et al. Robotic pollination-targeting kiwifruit flowers for commercial application. In: $7^{\text {th }}$ Asian-Australasian Conference on Precision Agriculture, 2017.

[98] Ye Y, He L, Wang Z, Jones D, Hollinger G A, Taylor M E, et al Orchard manoeuvring strategy for a robotic bin-handling machine. Biosystems Engineering, 2018; 169: 85-103.

[99] Zhang Y, Ye Y, Wang Z, Taylor M E, Hollinger G A, Zhang Q. Intelligent in-orchard bin-managing system for tree fruit production. In: Proc of the Robotics in Agr Workshop at the 2015 IEEE Int Conf Robotics \& Autom, 2015; 30: 1-4.

[100] Ye Y, Wang Z, Jones D, He L, Taylor M E, Hollinger G A, et al Bin-dog: A robotic platform for bin management in orchards. Robotics, 2017; 6(2): 12 . doi: 10.3390/robotics6020012.

[101] Jang W J, Lewis G, Hoachuck J, Slaughter D, Wilken K, Vougioukas S Vibration-reducing path tracking control for a strawberry transport robot In: 2014 ASABE Annual International Meeting. Montreal: ASABE, 2014; Paper number: 14194011. doi: 10.13031/aim.20141914011.

[102] Seyyedhasani H, Peng C, Jang W J, Vougioukas S G. Collaboration of human pickers and crop-transporting robots during harvesting-Part I: 
Model and simulator development. Computers \& Electronics in Agriculture, 2020; 172: 105324. doi: 10.1016/j.compag.2020.105324

[103] Qiao J, Sasao A, Shibusawa S, Kondo N. Mobile fruit grading robot-concept and prototype. In: 2004 ASAE Annual Meeting, 2004; pp.4173-4185. doi: 10.13031/2013.16725.

[104] Cubero S, Aleixos N, Albert F, Torregrosa A, Ortiz C, García-Navarrete O, et al. Optimised computer vision system for automatic pre-grading of citrus fruit in the field using a mobile platform. Precision Agriculture, 2014; 15(1): 80-94.

[105] Shamshiri R, Weltzien C, Hameed I A, Yule I, Grift T, Balasundram S K, et al. Research and development in agricultural robotics: A perspective of digital farming. Int J Agric \& Biol Eng, 2018; 11(4): 1-14.

[106] Shi Q, Liu D, Mao H, Shen B, Liu X, Ou M. Study on assistant pollination of facility tomato by UAV. In: 2019 ASABE Annual International Meeting, Boston: ASABE, 2019; 1900055. doi: 10.13031/aim.201900055.

[107] Berman S, Nagpal R, Halász Á. Optimization of stochastic strategies for spatially inhomogeneous robot swarms: A case study in commercial pollination. In: 2021 IEEE/RSJ International Conference Intelligent Robots \& Systems. San Francisco: IEEE, 2011; pp. 3923-3930. doi: 10.1109/IROS.2011.6094771.

[108] Chong V K, Monta M, Ninomiya K, Kondo N, Namba K, Terasaki E, et al. Development of mobile eggplant grading robot for dynamic in-field variability sensing:- manufacture of robot and performance test-. Eng Agr, Environ \& Food, 2008; 1(2): 68-76.

[109] Oudshoorn F. Mobile milking robot offers new grazing concept. Grassland Sci Europe, 2008; 13: 721-723.

[110] Chen Y, Feng K, Jiang Y, Hu Z. Design and research on six degrees of freedom robot evisceration system for poultry. In: Proc of 3rd Int Conf E-Business, Inf Management and Comput Science., 2020; pp. 382-386.

[111] Chen Y, Wan L, Liu Z. The study on recognition and location of intelligent robot system for eviscerating poultry. In: 2019 34rd Youth Academic Annual Conference of Chinese Association of Automation (YAC). Jinzhou, China: IEEE, 2019; pp. 499-503. doi: 10.1109/ YAC.2019.8787596.

[112] Doerfler R L, Martin R, Bernhardt H. Implications of robotic walkway cleaning for hoof disorders in dairy cattle. International Journal of Engineering Research and Application, 2017; 7(1): 98-104.

[113] Vroegindeweij B A, Blaauw S K, IJsselmuiden J M, Van Henten E J. Evaluation of the performance of PoultryBot, an autonomous mobile robotic platform for poultry houses. Biosystems Engineering, 2018; 174: 295-315.

[114] Vroegindeweij B. PoultryBot, a robot for poultry house applications: localisation, path planning, object recognition and performance evaluation. Doctor dissertation. Wageningen: Wageningen University, 2018; 218p.

[115] Chang C L, Xie B X, Wang C H. Visual guidance and egg collection scheme for a smart poultry robot for free-range farms. Sensors, 2020; 20(22): 6624. doi: 10.3390/s20226624

[116] Wang C H, Xie B X, Chang C L. Design and implementation of livestock robot for egg picking and classification in the farm. In: 2019 International Symposium on Electrical and Electronics Engineering (ISEE). Ho Chi Minh City: IEEE, 2019; pp. 161-165. doi: 10.1109/ ISEE2.2019.8921255.

[117] Joffe B P, Usher C T. Autonomous robotic system for picking up floor eggs in poultry houses. In: 2017 ASABE Annual International Meeting, 2017; 1700397. doi: 10.13031/aim.201700397.

[118] Mu S, Qin H B, Wei J, Wen Q K, Liu S H, Wang S C, et al. Robotic 3D vision-guided system for half-sheep cutting robot. Mathematical Problems in Engineering, 2020; 1: 1-11.

[119] Liu H W, Chen C H, Tsai Y C, Hsieh K W, Lin H T. Identifying images of dead chickens with a chicken removal system integrated with a deep learning algorithm. Sensors, 2021; 21(11): 3579. doi: 10.3390/s21113579.

[120] Xie B, Liu J, He M, Wang J, Xu Z. Research progress on autonomous navigation technology of agricultural robot. In: IEEE Cyber Int Conf., 2021; Paper number: 464

[121] Reina G, Milella A, Galati R. Terrain assessment for precision agriculture using vehicle dynamic modelling. Biosystems Engineering, 2017; 162: 124-139. doi: 10.1016/j.biosystemseng.2017.06.025.

[122] Zhang S, Song Y P, Xu B Y, Wang Z, Xu H J, Gao D S, et al. Design and experiment of omnidirectional agricultural measurement and control platform based on uC/OS system. Journal of Shandong Agricultural University (Natural Science Edition), 2018; 49(3): 438-443.

[123] Tian G Z, Zhou J, Gu B X. Slipping detection and control in gripping fruits and vegetables for agricultural robot. Int J Agric \& Biol Eng, 2018; 11(4): 45-51.

[124] Liu J Z, Bai X X, Ling P P, Mao H P. Complex collision model in high-speed gripping of fruit. Transactions of the CSAM, 2014; 45(4): 49-54, 172.

[125] Ji W, Qian Z J, Xu B, Chen G Y, Zhao D A. Apple viscoelastic complex model for bruise damage analysis in constant velocity grasping by gripper. Computers \& Electronics in Agriculture, 2019; 162 907-920.

[126] Zhou J, Zhang N, Meng Y M, Wang M J. Online estimation of tomato viscoelastic parameters during robot grasping. Transactions of the CSAM, 2017; 48(8): 26-32. (in Chinese)

[127] Li Z G, Zhang Z B, Thomas C. Viscoelastic-plastic behavior of single tomato mesocarp cells in high speed compression-holding tests. Innovative Food Science \& Emerging Technologies, 2016; 34: 44-50.

[128] Liu J Z, Li Z G, Li P P. Rapid damage-free robotic harvesting of tomatoes. China: Science Press \& Springer, 2021; 368p.

[129] Xiong Y, Ge Y Y, Liang Y L, Blackmore S. Development of a prototype robot and fast path-planning algorithm for static laser weeding. Computers \& Electronics in Agriculture, 2017; 142(PartB): 494-503.

[130] Bachche S, Oka K. Performance testing of thermal cutting systems for sweet pepper harvesting robot in greenhouse horticulture. Journal of System Design \& Dynamics, 2013; 7(1): 36-51.

[131] Liu J, Hu Y, Xu X Q, Li P P. Feasibility and influencing factors of laser cutting of tomato peduncles for robotic harvesting. African Journal of Biotechnology, 2011; 10(69): 15552-15563.

[132] Zhang K, Xu L, Zhang D. Design and analysis of a 4-PPPR parallel manipulator for strawberry harvesting in the ridge cultivation model. In: 2016 2nd International Conference Control Science \& Systems Engineering (ICCSSE). Singapore: IEEE, 2016; pp.248-251. doi 10.1109/CCSSE.2016.7784391.

[133] Bac C W, Roorda T, Reshef R, Berman S, Hemming J, can Henten E J. Analysis of a motion planning problem for sweet-pepper harvesting in a dense obstacle environment. Biosystems Engineering, 2016; 146: 85-97. doi: 10.1016/j.biosystemseng.2015.07.004.

[134] Van Herck L, Kurtser P, Wittemans L, et al. Crop design for improved robotic harvesting: A case study of sweet pepper harvesting. Biosystems Engineering, 2020; 192: 294-308. doi: 10.1016/j.biosystemseng. 2020.01.021.

[135] Bloch V, Degani A, Bechar A. A methodology of orchard architecture design for an optimal harvesting robot. Biosystems Engineering, 2018; 166: 126-137. doi: 10.1016/j.biosystemseng.2017.11.006.

[136] Shamshiri R R, Hameed I A, Pitonakova L, Weltzien C, Balasundram S K Yule I J, et al. Simulation software and virtual environments for acceleration of agricultural robotics: features highlights and performance comparison. Int J Agric \& Biol Eng, 2018; 11(4): 15-31. doi: 10.25165/j.ijabe.20181104.4032

[137] Mahmud M S A, Abidin M S Z, Mohamed Z, Rahman M K I A, Lida M. Multi-objective path planner for an agricultural mobile robot in a virtual greenhouse environment. Computers \& Electronics in Agriculture, 2019; 157: 488-499. doi: 10.1016/j.compag.2019.01.016.

[138] Wang H J, Zou X J, Liu C Y, Lu J, Liu T H. Study on behavior simulation for picking manipulator in virtual environment based on binocular stereo vision. In: 2008 Asia Simulation Conference-7th International Conference on System Simulation \& Scientific Computing. Beijing: IEEE, 2008; pp. 27-31. doi:10.1109/ASC-ICSC.2008.4675320.

[139] Grimstad L, From P. Thorvald II - a modular and re-configurable agricultural robot. IFAC-PapersOnLine, 2017; 50(1): 4588-4593.

[140] Oberti R, Marchi M, Tirelli P, Calcante A, Iriti M, Tona E, et al Selective spraying of grapevines for disease control using a modular agricultural robot. Biosystems Engineering, 2016; 146: 203-215.

[141] Levin M, Degani A. A conceptual framework and optimization for a task-based modular harvesting manipulator. Computers \& Electronics in Agriculture, 2019; 166: 104987. doi: 10.1016/j.compag.2019.104987.

[142] Mohamed A, ShawSutton J, Green B M, Andrews W, Rolley-Parnell E J Zhou Y, et al. Soft manipulator robot for selective tomato harvesting. In: 12th European Conf Precis Agr, 2019; pp.799-805. doi 10.3920/978-90-8686-888-9 99.

[143] Bartlett N, Tolley M, Overvelde J T B, Weaver J C, Mosadegh B, Bertold $\mathrm{K}$, et al. A 3D-printed, functionally graded soft robot powered by combustion. Science, 2015; 349(6244): 161-165.

[144] Devi M, Udupa G, Sreedharan P. A novel underactuated multi-fingered soft robotic hand for prosthetic application. Robotics \& Auto Syst, 2018; 
100: 267-277.

[145] Excell J. Fruit-picking robot solves automation challenge. 2015. Available: https://www.theengineer.co.uk/fruit-picking-robot-solvesautomation-challenge/. Accessed on [2015-10-16].

[146] Shea P, Floreano P. Intrinsic electro-adhesion for soft DEA-based grippers. 2017. Available: https://lmts.epfl.ch/electroadhesion. Accessed on [2017-08-03].

[147] Nishida T, Okatani Y, Tadakuma K. Development of universal robot gripper using $\mathrm{MR} \alpha$ fluid. Int J Humanoid Robotics, 2016; 13(4): 1650017. doi: 10.1142/S0219843616500171.

[148] Zhang F, Wang Y F, Teng S, Zheng L M, Wang J J, Chen Z J. Development of agricultural bionic four-legged robot: Effect of head movement adjustment on the stability of goats. Int J Agric \& Biol Eng, 2019; 12(4): 10-15. doi: 10.25165/j.ijabe.20191204.4287.

[149] Zhang C, Yang M J, Chen J, Jiang M, Ma Y C, Ji J. Energy consumption optimization model of agricultural hexapod robot with self-locking joints. Transactions of the CSAE, 2016; 32(18): 73-83. (in Chinese)

[150] Rong Y, Jin Z L, Cui B Y. Configuration analysis and structure parameter design of six-leg agricultural robot with parallel-leg mechanisms. Transactions of the CSAE, 2012; 28(15): 9-14. (in Chinese)

[151] Zhang J Z, Jin Z L, Chen G G. Kinematic analysis of leg mechanism of six-legged walking robot. Transactions of the CSAE, 2016; 32(9): 45-52. (in Chinese)

[152] Huang C, Chang C. Design and implementation of bio-inspired snake bone-armed robot for agricultural irrigation application. IFAC-Papers OnLine, 2019; 52(30): 98-101.

[153] Li M J, Zeng X, Xie R Z, Zhang Y H. Development of an inchworm-like soft gripper based on sma-drive. Mechanical Engineering \& Automation, 2018; 5: 35-37. (in Chinese)

[154] Quan L Z, Zhao L, Li X H, Zhang C B, Wang J S, Cheng G. Design and test of multifunctional dragonfly claws form bio-mimetic end effector. Transactions of the CSAM, 2017; 48(8): 33-42, 52. (in Chinese)
[155] Deng X L, Luo Z Y, Pang J Q, Zhang Y M, Yang C J, Li R Q. Design and experiment of bionic nondestructive handheld suction apple picker. Journal of China Agricultural University, 2019; 24(10): 100-108. (in Chinese)

[156] Potts S G, Neumann P, Vaissière B, Vereecken N J. Robotic bees for crop pollination: Why drones cannot replace biodiversity. Science of the Total Environment, 2018; 642: 665-667.

[157] Cheein F A, Steiner G, Paina G, Carelli R. Optimized EIF-SLAM algorithm for precision agriculture mapping based on stems detection. Computers \& Electronics in Agriculture, 2011; 78(2): 195-207.

[158] Soria P R, Sukkar F, Martens W, Arrue B C, Fitch R. Multi-view probabilistic segmentation of pome fruit with a low-cost RGB-D camera In: Iberian Robotics Conference., Cham: Springer, 2017; pp.320-331. doi: 10.1007/978-3-319-70836-2_27.

[159] Henten E, Hemming, J, van Tuijl B A J, Kornet J G, Meuleman J, Bontsema $\mathrm{J}$, et al. An Autonomous robot for harvesting cucumbers in greenhouses. Autonmous Robots, 2002; 13(3): 241-258.

[160] Yang L J, Pitla S, Yang Z D, Xia P P, Zhao C Y. Path tracking of mobile platform in agricultural facilities based on ultra wideband wireless positioning. Transactions of the CSAE, 2019; 35(2): 17-24. (in Chinese)

[161] Dimeas F, Sako D V, Moulianitis V C, Aspragathos N A. Design and fuzzy control of a robotic gripper for efficient strawberry harvesting. Robotica, 2015; 33(5): 1085-1098.

[162] Zhang C, Liu S Y, Huang X, Guo W, Li Y Y, Wu H. A stretchable dual-mode sensor array for multifunctional robotic electronic skin. Nano Energy, 2019; 62: 164-170.

[163] Wolfert S; Goense D, Sørensen C. A future internet collaboration platform for safe and healthy food from farm to fork. In: 2014 Annual SRII Global Conference. San Jose, CA, USA: IEEE, 2014; pp.266-273. doi:10.1109/SRII.2014.47.

[164] Dusadeerungsikul P, Nof S, Bechar A, Tao Y. Collaborative control protocol for agricultural cyber-physical system. Procedia Manufacturing 2019; 39: 235-242. 